\title{
Numerical investigation of the effect of manufacturing errors in pads on the behavior of tilting-pad journal bearings
}

\author{
Phuoc Vinh Dang', Steven Chatterton², Paolo Pennacchi², Andrea Vania ${ }^{2}$ \\ ${ }^{1}$ Department of Mechanical Engineering, The University of Danang - University of Science and \\ Technology, 54, Nguyen Luong Bang, Danang, Viet Nam. \\ ${ }^{2}$ Department of Mechanical Engineering, Politecnico di Milano, Via La Masa 1, I-20156 Milan, \\ Italy
}

\begin{abstract}
In this study, the effect of the manufacturing tolerances of the pad thickness or the assembly errors on the characteristics of a five-pad tilting-pad journal bearing is analyzed. In fact, the pad thickness errors correspond to a different preload factor or clearance for each pad. A sensitivity analysis was performed for several combinations of pad thickness for both load-on-pad and loadbetween-pad configurations using a thermo-elasto-hydro-dynamic model. Three cases of thickness variations were studied. The numerical results show that these manufacturing or assembly errors considerably affect on both the static and dynamic behaviours of the bearing.
\end{abstract}

Keywords: Manufacturing error; load-on-pad; load-between-pad; tilting-pad journal bearing; five pads; thermo-elasto-hydro-dynamic model.

\footnotetext{
${ }^{1}$ Corresponding author: Phuoc Vinh Dang.

Email address: dpvinh@dut.udn.vn
} 


\section{NOMENCLATURE}

$b_{G}$

$$
c_{G}
$$

C

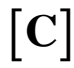

$\left[\mathbf{C}_{p a d}\right]^{k}$

$c_{x x}, c_{x y}, c_{y x}, c_{y y}$

$c_{\mu}$

$c_{p}$

$C_{p}$

$C_{b}$

D

$D_{H}, D_{P}$

e

E

$J_{P}$

$\Delta F_{x, o i l}, \Delta F_{y, o i l}$

$F_{P 0}$

h

$k$

$\left[\mathbf{K}_{p a d}\right]^{k}$ position of the barycentre with respect to the pivot point in the tangential direction (m)

position of the barycentre with respect to the pivot point in the radial direction $(\mathrm{m})$

tensor of mechanical properties $\left(\mathrm{N} / \mathrm{m}^{2}\right)$

linearized damping coefficient matrix

$k$-th pad damping matrix

linearized damping coefficients $(\mathrm{N}-\mathrm{s} / \mathrm{m})$

r.m.s error of the dynamic coefficient

heat capacity of the lubricant $(\mathrm{kJ} /(\mathrm{kg} \mathrm{K}))$

machined clearance (m)

assembled clearance (m)

Bearing diameter $(\mathrm{m})$

diameters of the bearing housing and back of pad (m)

eccentricity of journal centre (m)

Young's modulus of pivot and pivot housing $\left(\mathrm{N} / \mathrm{m}^{2}\right)$

mass moment of inertia of the pad with respect to pivot point $\left(\mathrm{kg} \cdot \mathrm{m}^{2}\right)$

horizontal and vertical oil-film forces in the frequency domain $(\mathrm{N})$

Static load acting on the pivot $(\mathrm{N})$

oil film thickness (m)

Heat conductivity (W/mK)

$k$-th pad stiffness matrix 


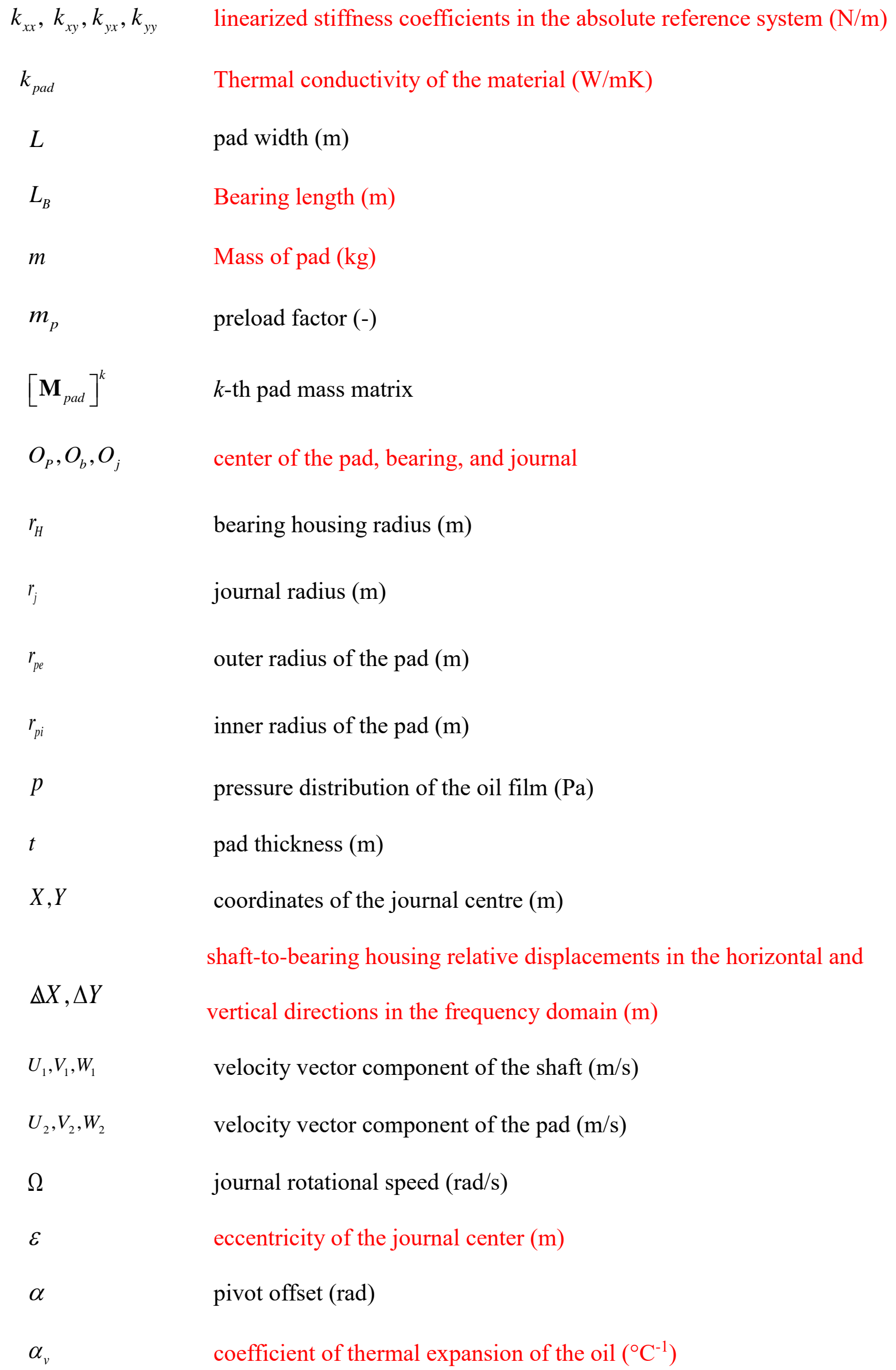




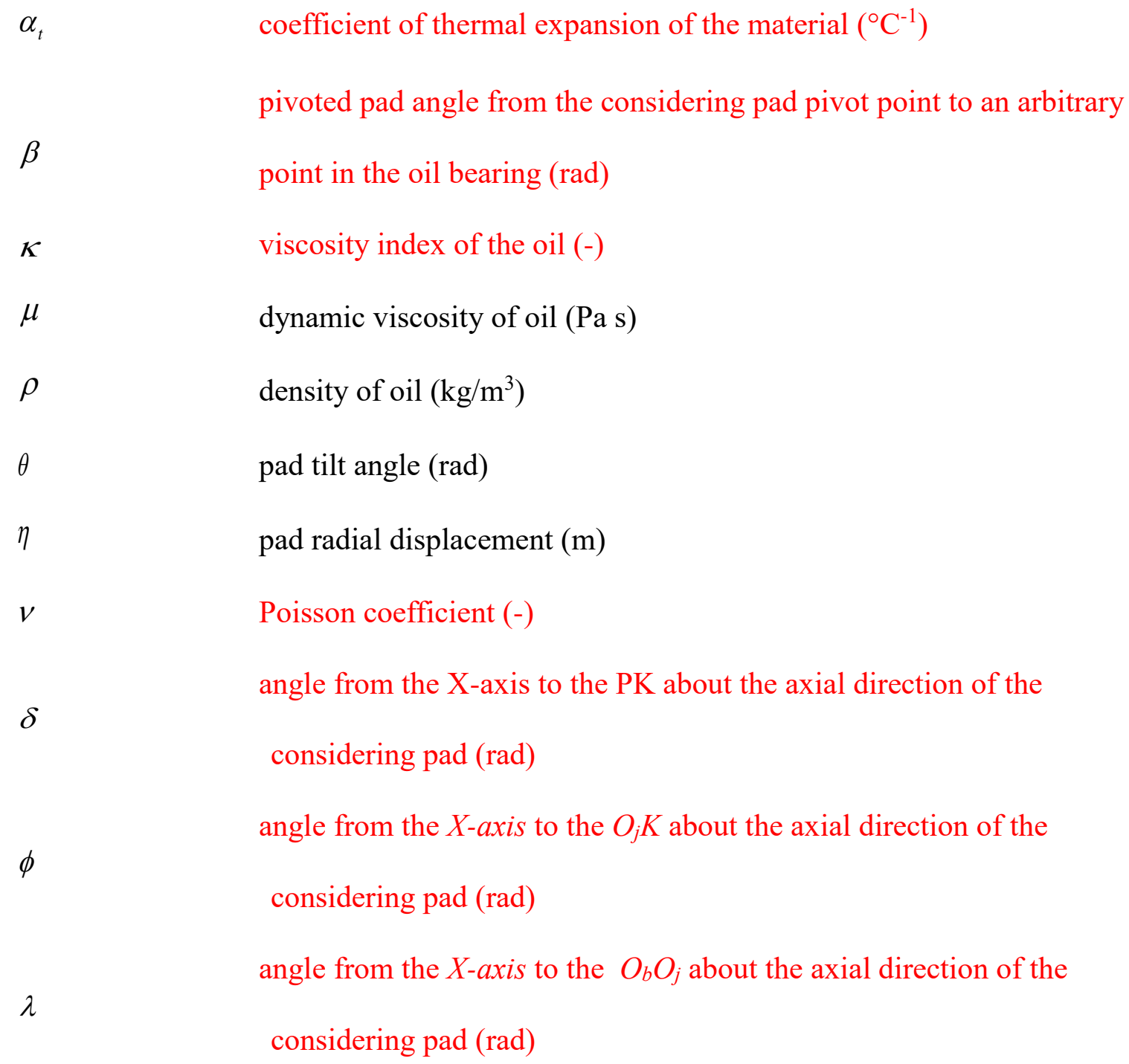




\section{INTRODUCTION}

Tilting-pad journal bearings (TPJBs) are more stable and efficient than conventional bearings, and have been commonly applied to many rotating machinery applications. The principal characteristic of TPJBs is their change of configuration to adjust to every working condition, which generates several convergent-divergent gaps around the circumference and makes the system highly stable. Since Lund [1] developed a numerical method to calculate the dynamic coefficients for TPJBs, extensive theoretical and experimental studies on dynamic and stability analysis have been conducted. To develop TPJBs, many useful techniques have been used, such as the NewtonRaphson method, pad assembly technique, finite elements method, and Genetic Algorithm to calculate the static and dynamic characteristics of journal bearings and mechanical systems. In general, the nominal geometry of the bearing is assumed in these numerical models. The manufacturing process of the bearing can make the bearing clearance different from the theoretical one.

Jones et al. [2] theoretically studied the effects of bearing clearance and pad clearance on the steady-state and dynamic behaviour in TPJBs. They concluded that the pad clearance hardly affected the $K_{y y}$ term at small values of the bearing clearance ratio, and the bearing clearance had a stronger effect than the pad clearance. The effects of the preload factor and clearance ratio on the performance of the TPJB were also investigated in [3]-[8].

Strzelecki [9] investigated the static and dynamic features of a five-pad TPJB, which has a nonsymmetric pad support, using a thermo-hydro-dynamic (THD) model. He concluded that the lengthto-diameter ratio only affected the direct terms of the stiffness coefficients, whereas the machined clearance affected all dynamic coefficients.

Wilkes et al. [10] studied the effects of the pad and pivot flexibility in forecasting the dynamic coefficients for the TPJB. They considered the variations of the bearing clearance with the working temperature and determined the differences between predicted and measured dynamic coefficients 
as a function of frequency. A clearance profile with a pentagonal shape was obtained as a function of the working temperature. Hot and cold clearance profiles were plotted, and the measured hot clearance profiles were almost $30 \%$ smaller than the measured cold clearance profiles. The effect of using an unreduced bearing model versus a reduced bearing model in a stability determination for a realistic rotor-bearing system was evaluated.

Moreover, most papers in the literature evaluate the dynamic behaviour of TPJBs by assuming that all pads have the same nominal geometry, which is a circular periodicity of the bearing geometry. In actual applications, manufacturing tolerances of the pads and assembly errors occur, which makes the actual "mistuned" bearing have a non-nominal geometry [11]-[17]. In particular, the manufacturing tolerance can have the same order of magnitude as the oil film thickness.

Assembly errors can occur because several mechanical parts that correspond to the pivots and shims are often used to adjust the position of the pads.

Fillon [18] and [19] investigated the effect of manufacturing tolerances on the behaviour of a five-pad TPJB by considering the same geometry for all pads.

The effect of pad clearance and preload variation on the dynamic coefficients of a five-pad TPJB was also investigated using a numerical model in [20]-[21]. These papers concluded that the manufacturing tolerances might introduce major effects on the dynamic coefficients of a TPJB. However, these two researches only focused on the dynamic coefficients of the bearings installed in a LOP configuration as a function of excitation. Besides, the considered variation of the preload nominal value was only $10 \%$ on one pad individually and $\pm 10 \%$ on two pads simultaneously.

In this paper, the effects of manufacturing error on one pad individually and two pads simultaneously, i.e., the effects of the geometry asymmetry, on the TPJB performances, such as the dynamic coefficients, shaft locus, minimum oil film thickness and maximum pressure, have been evaluated using a thermo-elasto-hydro-dynamic (TEHD) model. The model here is based on the THD model that was introduced and validated in [17] by the same authors. The numerical simulation considers both pad and pivot flexibility and a simple thermal model only for the oil film 
temperature to accurately predict the performance of TPJBs. Several five-pad TPJBs with different thicknesses in one pad individually and two pads simultaneously for both load-on-pad (LOP) and load-between-pad (LBP) configurations are analytically modeled for a range of rotational speeds, and the results are compared. Furthermore, the case in which the relative direction between the load and the bearing reference system changes in a full revolution has been also investigated. The bearing with nominal dimensions is used as the reference.

\section{TEHD BEARING MODEL}

A thorough description of the mathematical model to evaluate the static and dynamic coefficients is provided in [17] and will not be discussed in detail here. The bearing is a five-shoe rocker-backed TPJB.

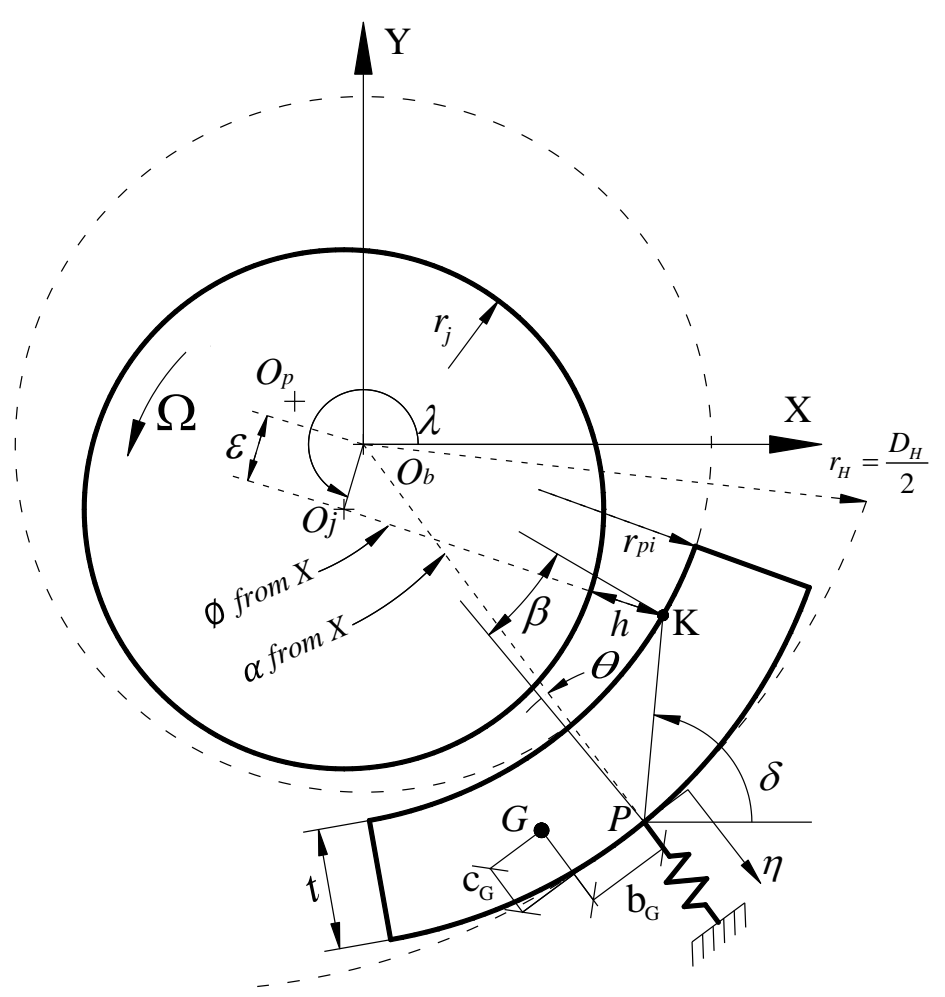

Fig. 1. Geometry and coordinate for a single pad [17]

Considering the detailed geometry of a single pad in Fig. 1, the pad tilts by angle $\theta$ about the line contact $\mathbf{P}$. The flexibility of the pivot [10] is considered in the model based on the displacement 
of the pivot position along the radial direction $\eta$. Therefore, the degrees of freedom of the system, in addition to each pad deformation, are:

$$
z=\left[\begin{array}{lllllll}
x & y & \theta^{(1)} & \eta^{(1)} & \cdots & \theta^{(5)} & \eta^{(5)}
\end{array}\right]
$$

The hydrodynamic model is based on the well-known Reynolds equation:

$$
\frac{\partial}{\partial x}\left(\frac{\rho h^{3}}{\mu} \frac{\partial p}{\partial x}\right)+\frac{\partial}{\partial z}\left(\frac{\rho h^{3}}{\mu} \frac{\partial p}{\partial z}\right)=6\left[\left(U_{1}-U_{2}\right) \frac{\partial}{\partial x}(\rho h)+\rho h \frac{\partial}{\partial x}\left(U_{1}+U_{2}\right)+2 \rho\left(V_{2}-V_{1}\right)\right]
$$

where $x$ is the tangential direction and $z$ is the axial direction.

The effect of temperature on the dynamic viscosity $\left(\mu(T)=\mu_{40^{\circ} \mathrm{C}} \exp \left[\kappa\left(T_{40^{\circ} \mathrm{C}}-T\right)\right]\right)$ and oil density $\left(\rho(T)=\rho_{40^{\circ} \mathrm{C}}\left[1+\alpha_{v}\left(T_{40^{\circ} \mathrm{C}}-T\right)\right]\right)$ is considered using a simple two-dimensional thermal model, governed, at steady state, by the energy equation:

$$
\rho c_{p}\left(u \frac{\partial T}{\partial x}+w \frac{\partial T}{\partial z}\right)=k_{O I L}\left(\frac{\partial^{2} T}{\partial x^{2}}+\frac{\partial^{2} T}{\partial z^{2}}\right)+\mu\left[\left(\frac{\partial u}{\partial y}\right)^{2}+\left(\frac{\partial w}{\partial y}\right)^{2}\right]
$$

where $c_{p}$ and $k_{L}$ are the heat capacity and the conductivity of the lubricant respectively.

Equation (3) has been integrated using a finite difference method, where adiabatic conditions at the shaft, pad surfaces and constant oil temperature in the oil film thickness direction are considered.

A three-dimensional model can be used for the accurate estimation of the temperature in the system [28], but requires high computational time. An example of it is shown in Fig. 2 for the nominal bearing described in the paper when a static load of $5 \mathrm{kN}$ is applied in the vertical direction (LOP for pad \#1) at a rotational speed of $5500 \mathrm{rpm}$. In Fig. 2 the fixed temperature of $40^{\circ} \mathrm{C}$ is assumed as boundary condition for the inlet surface of the oil in the pad. 


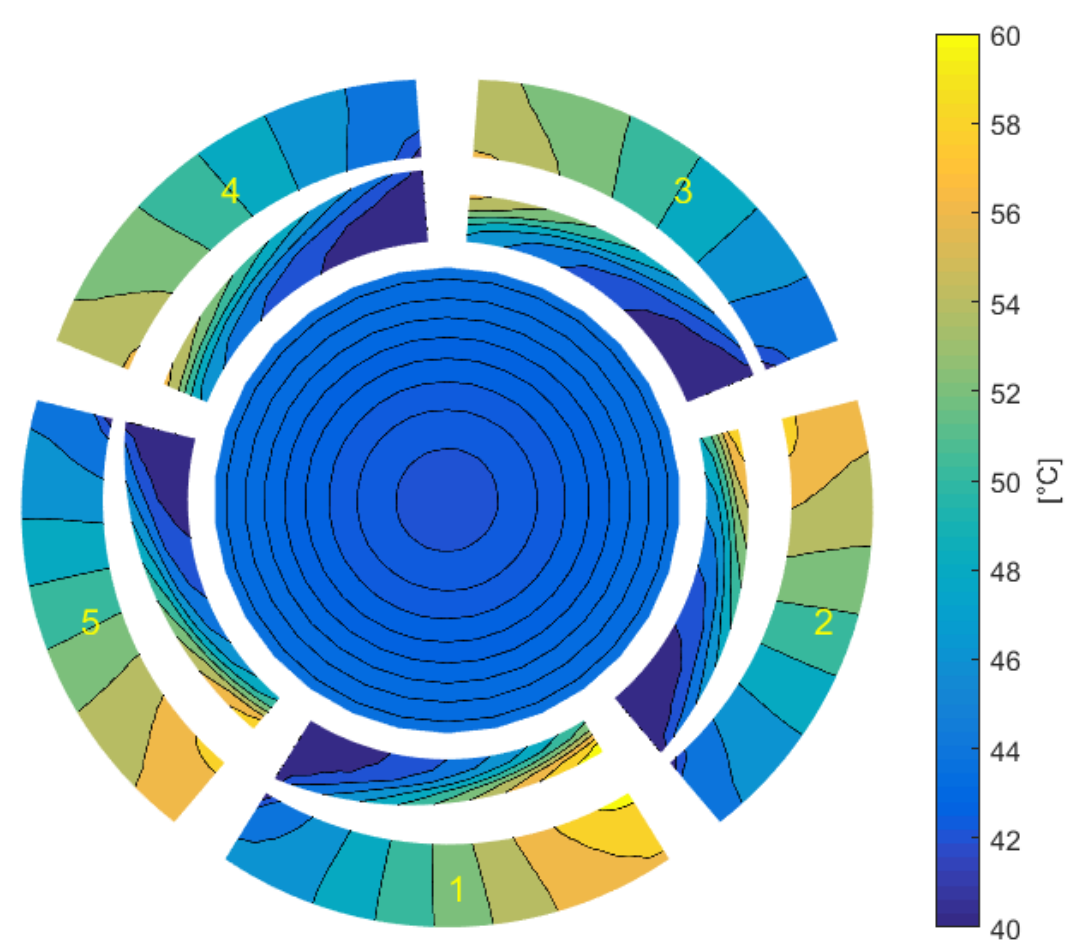

Fig. 2. Cross section (middle plane) of the temperature distribution in the nominal TPJB at the static load of $5 \mathrm{kN}$ (in the vertical direction) and the rotational speed of $5500 \mathrm{rpm}$ obtained with a threedimensional thermal model.

The average dynamic viscosity of the oil in the oil film thickness direction, obtained by the three-dimensional model and required by eq. (2), is quite close to the viscosity obtained by the twodimensional model. The r.m.s. error of the dynamic viscosity defined as $e_{\mu}=\left|\left(\mu_{2 D}-\bar{\mu}_{3 D}\right) / \bar{\mu}_{3 D}\right|$ between the two models is about $2.7 \%$ (maximum 5\%) for the nominal TPJB and about $3.5 \%$ (maximum 8\%) in the worst condition (see Table 3) analyzed in the paper with the highest temperature. Without loss of generality, the two-dimensional model has been used in the simulations shown in the paper due to the high computational time of the three-dimensional thermal model.

The effect of the deformation of the pad as a result of the pressure distribution and the thermal expansion has been considered and evaluated by means of a finite element analysis of the pad. The resultant deformation of the pad surface has been transformed in the change of oil-film thickness. In 
particular, the temperature distribution in the pad at the steady state is governed by the following equation:

$$
-\nabla\left(k_{P A D} \nabla T\right)=0
$$

where $k_{P A D}$ is the thermal conductivity of the material. By considering an isotropic material, the deformation of the pad (displacement $\mathbf{u}$ ) due to thermal and mechanical stresses is governed by the elasticity equation [27]:

$$
-\nabla(C \otimes \nabla \mathbf{u})=\frac{E}{1-2 v} \alpha_{t} \nabla T
$$

where $C$ is the tensor of mechanical properties, $\alpha_{t}$ is the thermal expansion coefficient, $E$ is Young's modulus, and $v$ is Poisson's ratio of the material.

In the finite element analysis, a tetrahedral mesh with 98,428 nodes has been considered (see Fig. 3b). Different values of material properties such as Young's modulus, the thermal conductivity and the expansion coefficients for the steel of the pad base and the Babbitt metal have also been considered to take into account the overall deformation as a result of the mechanical crowning; the deformation in the upper surface mainly results from the compression of the Babbitt metal and the thermal crowning of the pad. The pad model includes the steel part of the pad base $\left(E_{\text {STEEL }}=206 \mathrm{GPa}\right)$ and the $3 \mathrm{~mm}$ thick Babbitt layer $\left(E_{B A B B I T}=40 \mathrm{GPa}\right)$ on the pad sets. The nominal thickness of each pad is $16.00 \mathrm{~mm}$. The properties of the two materials are listed in Table 1.

The pressure and the temperature fields obtained from the Reynolds equation and the thermal model for the oil-film have been applied to the surface of the pad. A convective boundary condition with convection coefficients $q=50 \mathrm{~W} / \mathrm{m}^{2}$ is applied on the other surfaces of the pad for the evaluation of the pad temperature distribution. Additional boundary conditions are applied on all surfaces of the pad to consider the traction stresses for the evaluation of the thermal deformation. 
Fig. 4 shows the deformation of all pads for the nominal TPJB when a static load of $5 \mathrm{kN}$ is applied in the vertical direction (LOP for pad \#1) at a rotational speed of $5500 \mathrm{rpm}$.

(a)

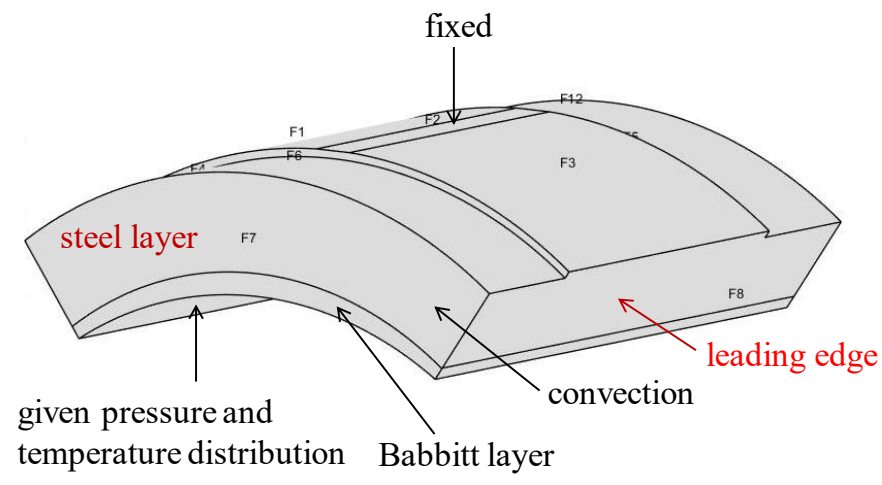

(b)

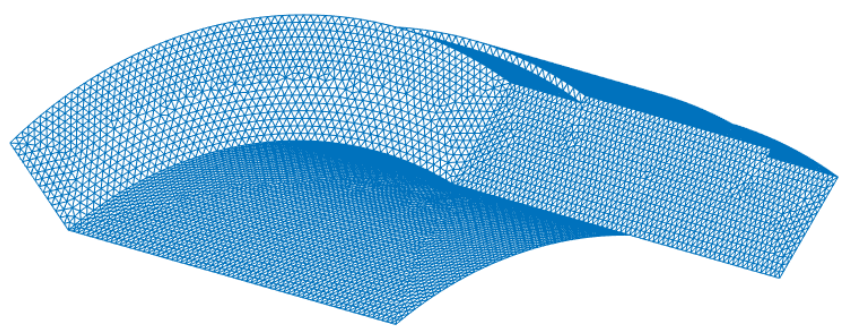

Fig. 3. Boundary conditions (a) and pad mesh (b).

Table 1. Properties of pad materials

\begin{tabular}{llll}
\hline Parameter & & Babbitt & Steel \\
\hline Young's modulus [GPa] & $E$ & 40 & 206 \\
Poisson's ratio & $v$ & 0.3 & 0.3 \\
Thermal expansion coefficient $[1 / \mathrm{K}]$ & $\alpha_{t}$ & $12 \times 10^{-6}$ & $24 \times 10^{-6}$ \\
Heat conductivity $[\mathrm{W} /(\mathrm{m} \mathrm{K})]$ & $k$ & 26 & 54 \\
\hline
\end{tabular}




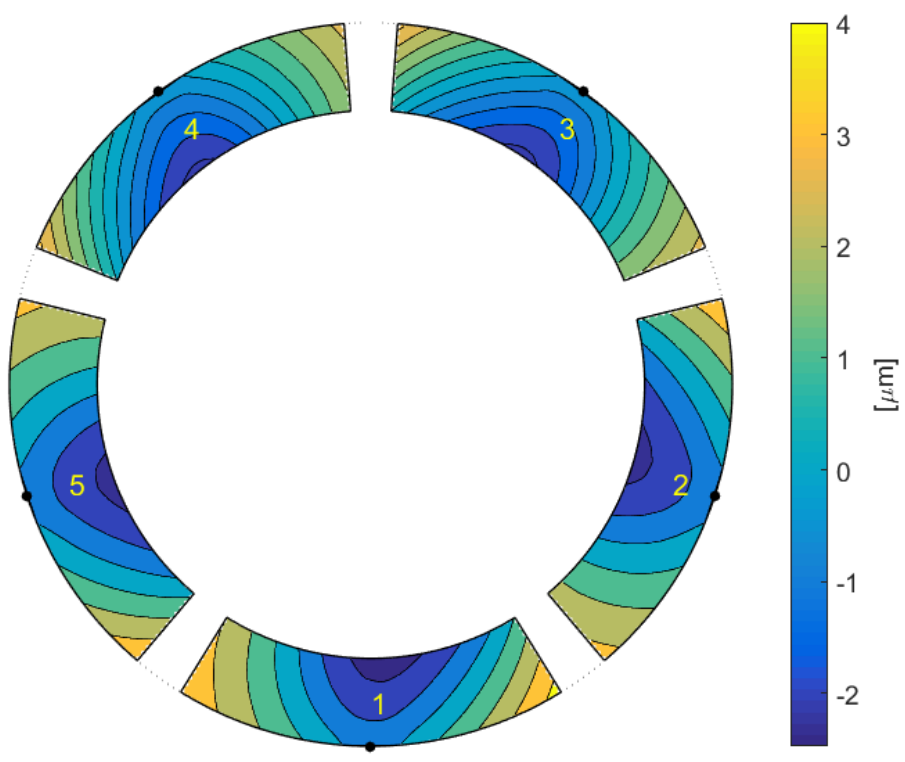

Fig. 4. Cross section (middle plane) of the radial deformation of pads in the nominal TPJB at the static load of $5 \mathrm{kN}$ (in the vertical direction) and the rotational speed of $5500 \mathrm{rpm}$.

In Fig. 4 it is possible to highlight the thermal crowning of the pad (leading and trailing edges of the pad) and the expansion of the centre of the pad in the radial direction towards the shaft.

The dynamic coefficients of the bearing because of the lateral motion of the shaft (represented by four impedance coefficients of the impedance matrix $\left[\mathbf{Z}_{B R G}\right]$ in eq. (6)), are obtained in eq.(7) by reducing the complete set of impedance coefficients of the pads (impedance matrix $[\mathbf{Z}]^{k}$ in eq. (8)), assuming a harmonic motion of the system at frequency $\omega[22]$ :

$$
\begin{aligned}
& {\left[\begin{array}{l}
\Delta F_{x, o i l} \\
\Delta F_{y, o i l}
\end{array}\right]=-\left[\mathbf{Z}_{B R G}\right]\left[\begin{array}{l}
\Delta X \\
\Delta Y
\end{array}\right]=-\left[\begin{array}{ll}
Z_{x x} & Z_{x y} \\
Z_{y x} & Z_{y y}
\end{array}\right]\left[\begin{array}{c}
\Delta X \\
\Delta Y
\end{array}\right]} \\
& {\left[\mathbf{Z}_{B R G}\right]=-\sum_{k}\left(\left[\begin{array}{ll}
Z_{x x} & Z_{x y} \\
Z_{y x} & Z_{y y}
\end{array}\right]^{k}-\left[\begin{array}{cc}
Z_{x \theta} & Z_{x \eta} \\
Z_{y \theta} & Z_{y \eta}
\end{array}\right]^{k}\left(\left[\begin{array}{cc}
Z_{\theta \theta} & Z_{\theta \eta} \\
Z_{\eta \theta} & Z_{\eta \eta}
\end{array}\right]^{k}-\omega^{2}\left[M_{p a d}\right]^{k}+\mathrm{i} \omega\left[C_{p a d}\right]^{k}+\left[K_{p a d}\right]^{k}\right)^{-1}\left[\begin{array}{ll}
Z_{\theta x} & Z_{\theta y} \\
Z_{\eta x} & Z_{\eta y}
\end{array}\right]^{k}\right)}
\end{aligned}
$$




$$
[\mathbf{Z}]^{k}=[\mathbf{K}]^{k}+\mathrm{i} \omega[\mathbf{C}]^{k}=\left[\begin{array}{cccc}
z_{x x} & z_{x y} & z_{x \theta} & z_{x \eta} \\
z_{y x} & z_{y y} & z_{y \theta} & z_{y \eta} \\
z_{\theta x} & z_{\theta y} & z_{\theta \theta} & z_{\theta \eta} \\
z_{\eta x} & z_{\eta y} & z_{\eta \theta} & z_{\eta \eta}
\end{array}\right]^{k}
$$

where $[\mathbf{K}]^{k}$ and $[\mathbf{C}]^{k}$ are the linear stiffness and damping coefficient matrices, respectively, which are calculated for the $k$-th pad, and:

$$
\begin{aligned}
& {\left[M_{p a d}\right]^{k}=\left[\begin{array}{cc}
J_{P} & m b_{G} \\
m b_{G} & m
\end{array}\right]^{k}} \\
& {\left[C_{p a d}\right]^{k}=\left[\begin{array}{cc}
c_{\theta} & 0 \\
0 & c_{\eta}
\end{array}\right]^{k}} \\
& {\left[K_{p a d}\right]^{k}=\left[\begin{array}{cc}
k_{\theta} & 0 \\
0 & k_{\eta}
\end{array}\right]^{k}}
\end{aligned}
$$

where $J_{P}$ is the mass moment of inertia of the pad, $m$ is the mass, and $b_{G}$ is the position of the barycentre. The pivot stiffness of the pivot along direction $\eta$, which depends on the static load $F_{P 0}$ acting on the pivot, is obtained using the contact Hertz theory as in [23]:

$$
K_{\text {rocker back }}=\frac{\pi E L}{2\left(1-v^{2}\right)}\left(\frac{2}{3}+\ln \frac{\pi E L\left(D_{H}-D_{P}\right)}{4 F_{P 0}\left(1-v^{2}\right)}\right)
$$

where $D_{H}$ and $D_{P}$ are the diameters of the bearing housing and the back of pad respectively.

Additional details about the terms in Eqs.(6)-(9) can be found in [17].

In conclusion, for a given static load, the following conditions must be satisfied:

- convergence of the pressure distribution in each pad;

- convergence of the temperature distribution in each pad;

- equilibrium of the forces on each pad;

- convergence of pad deformation on each pad; 
- equilibrium of the forces on the shaft for the given static load.

The results of the numerical simulations have been obtained by using the code developed by the authors and based on Matlab®. The Optimization toolbox has been used for solving the equilibrium position of the system (pads and shaft) and the Partial Differential Equation Toolbox for solving the three-dimensional thermal model for the temperature distribution and the threedimensional structural-mechanics model for the pad deformation.

The main program flowchart is shown in Fig. 5. 


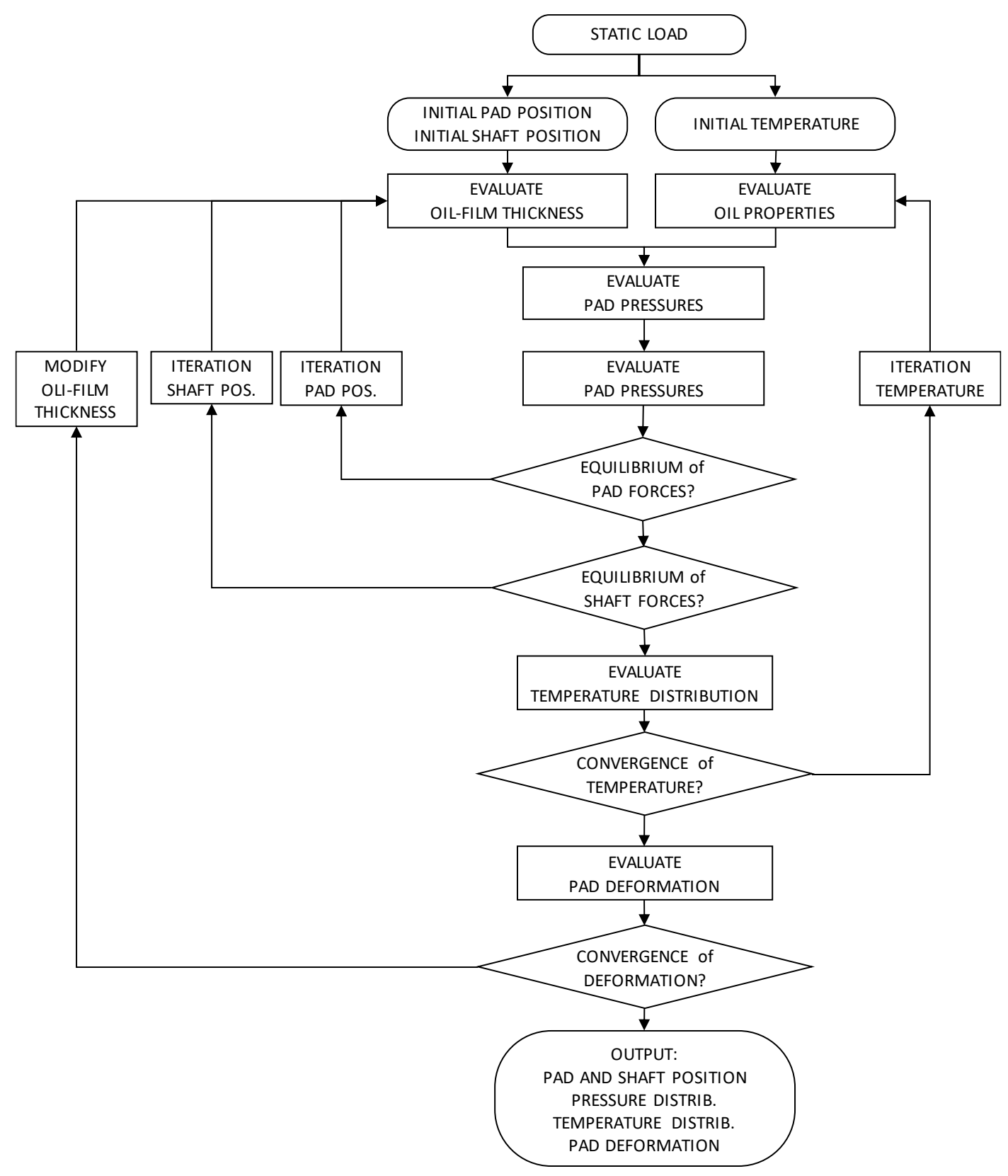

Fig. 5 Main program flowchart.

\section{BEARING DESCRIPTION}

Numerical investigations were performed using the nominal geometry of a five-pad TPJB, which is currently installed in the test rig from the Dept. of Mechanical Engineering of Politecnico di Milano. The actual bearing was affected by an asymmetry of the geometry because of manufacturing errors in some pads. The authors used the experimental results in [17] to tune and 
validate the model. In this paper, only numerical analyses were performed to investigate the effect of the manufacturing error on the behaviour of the bearing.

In particular, for rocker-backed pad TPJBs the manufacturing uncertainties can occur on the bearing housing diameter, the pad radii and the pad thickness. The diameter of the bearing housing affects the position of the pivots whereas the radius of curvature of the back of the pad has a negligible influence on the bearing behavior. Taking into account the manufacturing process of the pads, the main cause of the error is due to the positioning of the pad during the machining of the Babbitt surface, resulting in error in pad thickness. Furthermore, from the measurements of the geometry of the pads used by the authors in the experiments in [17], the maximum deviations of the circularity of the bearing housing and the pad radii were one order of magnitude lower than the pad thicknesses.

Therefore in the paper only the pad thickness has been considered as manufacturing error. Nominal values have been assumed for the bearing housing diameter and the pad radii.

In particular, three cases of thickness variation were considered for the parametric study: (i) individual thickness variations on one pad - LOP configuration (see Fig. 6(a)); (ii) simultaneous thickness variations on two pads - LOP configuration (see Fig. 6(b)); and (iii) simultaneous thickness variations on two pads - LBP configuration (see Fig. 6(c)).

Case 1

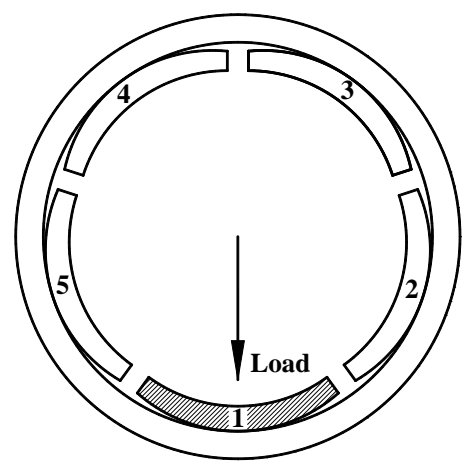

(a)
Case 2

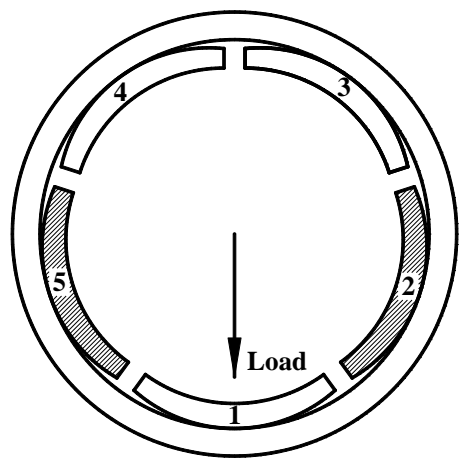

(b)
Case 3

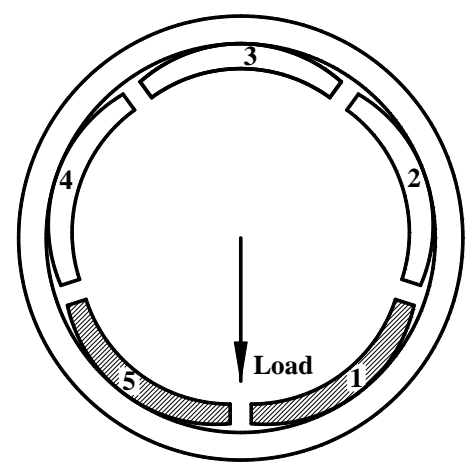

(c)

Fig. 6. Three cases of thickness variation considered in the parametric study. 
The TPJB in this paper has five pads with line contact rocker-backed pad pivots. The thickness tolerances of the pads were selected in the range of $\pm 30 \mu \mathrm{m}$, with steps of $10 \mu \mathrm{m}$ (from $15.970 \mu \mathrm{m}$ to $16.030 \mu \mathrm{m})$. These tolerances might be slightly larger than those used by bearing companies and manufacturers. For example, for the nominal dimension of $16.000 \mathrm{~mm}$ of pad thickness in the paper, the common IT6 tolerance index corresponds to a tolerance range of $11 \mu \mathrm{m}$. Nevertheless, deviations from the nominal dimensions can occur during the assembly phase of the bearing as in the case of bearing equipped with shims.

The considered bearing had the nominal diameter of $100 \mathrm{~mm}$ and the length-to-diameter ratio (L/D) of 0.7. The rotational speed ranges was $500-5500 \mathrm{rpm}$, whereas the constant static load of $5 \mathrm{kN}$ was used in the numerical simulations. The geometric and operating parameters of the bearings are listed in Table 2 .

Table 2. Bearing geometric characteristics and operating conditions.

\begin{tabular}{lll}
\hline Item & Symbol & Value/Span \\
\hline Number of pads & - & 5 \\
Configuration w.r.t bearing housing & - & $\mathrm{LOP}$ \\
Journal nominal diameter & $D$ & $100 \mathrm{~mm}$ \\
Bearing length & $L_{B}$ & $70 \mathrm{~mm}$ \\
Nominal machined clearance & $C_{p}$ & $0.130 \mathrm{~mm}$ \\
Lubricant & - & ISO VG46 \\
Inlet oil temperature & & $40^{\circ} \mathrm{C}$ \\
Rotational speed range & - & $500-5500 \mathrm{rpm}$ \\
Static load & - & $5 \mathrm{kN}$ \\
Pad thickness - considering pad(2) & $t$ & $15.97-16.03 \mathrm{~mm}$ \\
Pad thickness - remaining pads (nominal) & $t$ & $16.00 \mathrm{~mm}$ \\
\hline
\end{tabular}

In the first case in Fig. 6(a), the variation of thickness in one pad (pad \#1) was investigated for an LOP configuration. By varying the bearing configuration such as the absolute position of pad \#1, as shown in Fig. 7, some additional cases were studied. In Fig. 7, the bearing angular position 
changed, i.e., the bearing rotated; the static load maintained its absolute direction but changed its relative direction with respect to the considered pad (pad \#1). For a fixed bearing position (pad \#1 fixed in the bottom direction), this corresponds to the effect of the load directions on the static and dynamic characteristics of TPJBs, which are affected by a manufacturing error in one pad. In fact, high bearing loads outside the vertical direction may occur in industrial rotating machines, such as gear boxes or turbo-generators, because of bad alignment conditions of the shaft line [24]. This issue can be simply simulated by rotating the static load direction. In the paper, the static load was fixed in the downward direction, and the angular position of the bearing changed in a full revolution (see Fig. 7) [11],[15] by considering the constant speed of $1200 \mathrm{rpm}$ and the constant static load of $5 \mathrm{kN}$ (some experimental results for these operating conditions are reported in [17]). For all considered cases, the shaft rotated in the anticlockwise direction.
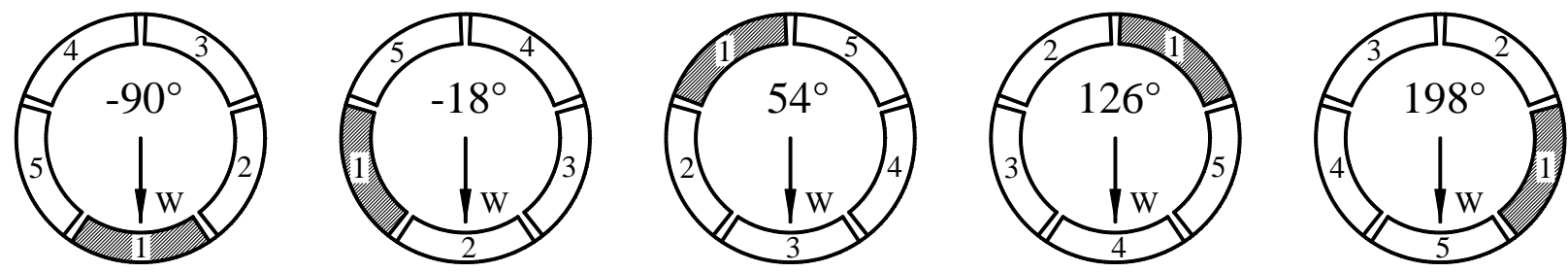

Fig. 7. Additional cases, in which the thickness varies for pad \#1 and the angular position of the bearing changes.

Note that the assembled clearance $C_{b}$ of the TPJB was calculated using the value of pad thickness. Therefore, the variation of pad thickness causes the change in assembled clearance $C_{b}$. In addition, because the preload factor $\left(m_{p}=1-C_{b} / C_{p}\right)$ depends on the assembled and machined clearances, any variation of $C_{b}$ automatically alters the preload factor $m_{p}$. Table 3 shows the thickness of pad \#1 and the corresponding assembled clearances and preload factors. 
Table 3. Assembled clearances and preload factors that correspond to the variations of the pad thickness.

\begin{tabular}{c|cc}
\hline $\begin{array}{c}\text { Thickness of pad } \\
{[\mathrm{mm}]}\end{array}$ & $\begin{array}{c}\text { Assembled clearance } \\
C_{b}[\mu \mathrm{m}]\end{array}$ & $\begin{array}{c}\text { Preload factor } \\
m_{p}\end{array}$ \\
\hline 15.970 & 90 & 0.308 \\
15.980 & 80 & 0.385 \\
15.990 & 70 & 0.462 \\
16.000 (nominal) & 60 & 0.538 \\
16.010 & 50 & 0.615 \\
16.020 & 40 & 0.692 \\
16.030 (worst condition) & 30 & 0.769 \\
\hline
\end{tabular}

\section{RESULTS AND DISCUSSIONS}

In this paper, the bearing performance was compared in terms of shaft locus, minimum oil film thickness, maximum pressure, maximum oil temperature in the pad, and dynamic coefficients.

\subsection{Share of load}

The main effect of the variation of the assembled clearance or the preload factor given by a change in pad thickness is a different share of load carrying for each pads due to the different pressure distributions.

The cross section (middle plane) of the pressure distribution in the pads for several values of the pads thickness is shown in Fig. 8 at the static load of $5 \mathrm{kN}$ (in the vertical direction) and the rotational speed of $5500 \mathrm{rpm}$. In Fig. 8 the share in load of the pads is also plotted.

In nominal TPJB (all the pads with the same thickness) the maximum pressure occurs in the loaded pads (pad \#1 for the first two cases and pads \#1 and \#5 for case 3 ). In general, the increase in the pad thickness corresponds to the increase in the pressure for the pad(s) in which the pad thickness variation occur and for pads placed in the opposite direction as in pads \#3 and \#4 for the first two cases. For the third case the pressure increase in all the pads of the bearing. 
An opposite trend occurs for the loaded pad \#1 of the case 2, where the pressure and the load on the pad decreases, due to the increase of the load in the pads \#2 and \#5, as a consequence of the increase of the pad thickness. 

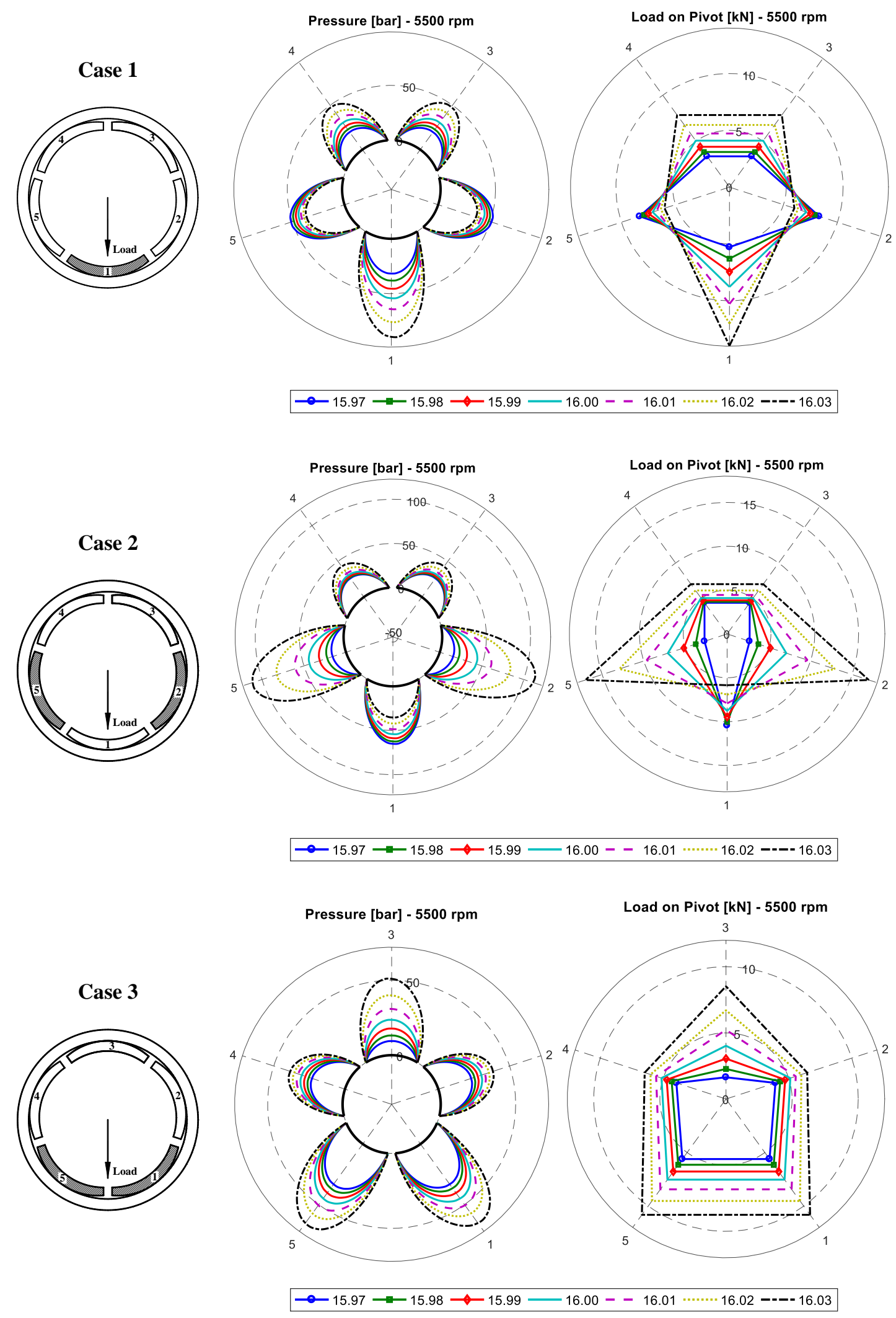

Fig. 8. Pressure distribution and share in load of the pads. 


\subsection{Shaft locus}

For a bearing in practice, the static loads (gravity load, external static load, etc.) are predetermined, whereas the static equilibrium position is unknown. Fig. 9 shows the shaft centres of the bearing for several pad thickness values and shaft speeds $(500-5500 \mathrm{rpm}$ with steps of $250 \mathrm{rpm}$ ) for the three cases.

Note that the static positions of the shaft centre in Fig. 9 are the amount of static shaft sink/float below/above the bearing centre. The 16.00-bearing corresponds to the nominal bearing.

When the rotational speed increases, the centre of the shaft clearly tends to "climb" to the equilibrium position of the bearing centre.

The trend of the static position for an increase in pad preload or pad thickness is identical for all three cases: the centre of the shaft moves to the centre of the bearing.

This effect is more evident if the variation of the pad thickness occurs in the loaded pad(s) (cases 1 and 3) and less evident for case 2. Furthermore, assuming the same variation of the pad thickness, the variation in two pads (case 3) causes a larger displacement of the shaft centre than the variation in one pad (case 1). 

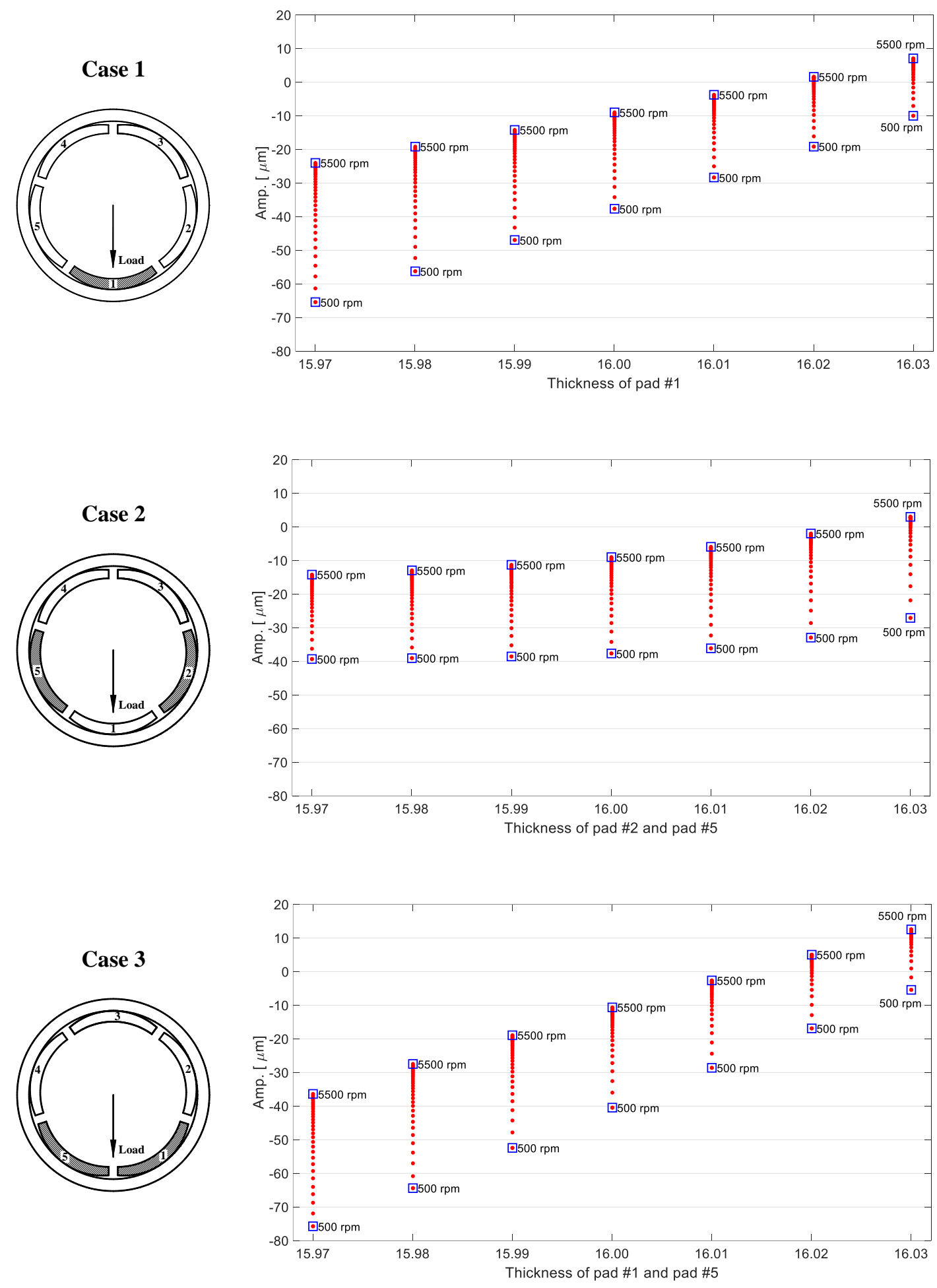

Fig. 9. Static position of the shaft centre vs. the rotational speed. 


\subsection{Minimum oil film thickness}

The effect of manufacturing errors on the overall minimum oil film thickness under various rotational speeds is shown in Fig. 10. In general, the minimum film thickness in the bearing increases with the rotational speed. The plot also shows that the effect is more visible at high rotational speeds. In general the minimum oil-film thickness decreases in the pad(s) in which the variation of the pad thickness occurred. In all three cases, a low minimum oil film thickness is obtained if the bearing is equipped with one or two pads with larger thicknesses (or larger preload factors) than the other pads. Conversely, the highest minimum oil film thickness is obtained with the nominal geometry or when one or two pads have smaller pad thicknesses (smaller preload factors) than the others. 

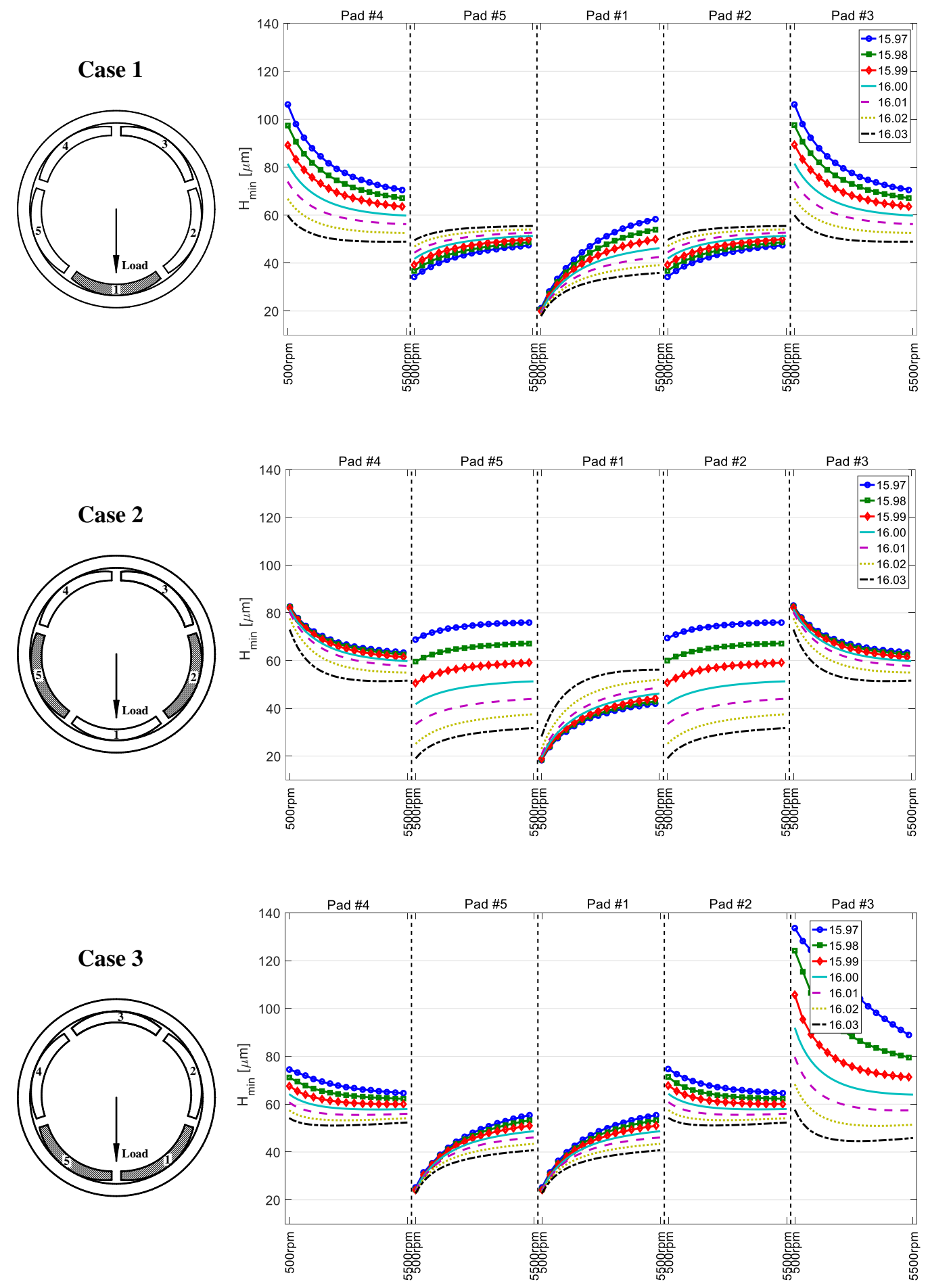

Fig. 10. Minimum oil film thickness as a function of the rotational speed. 
The trend of the maximum pressure of all bearings (Fig. 11) is notably similar.
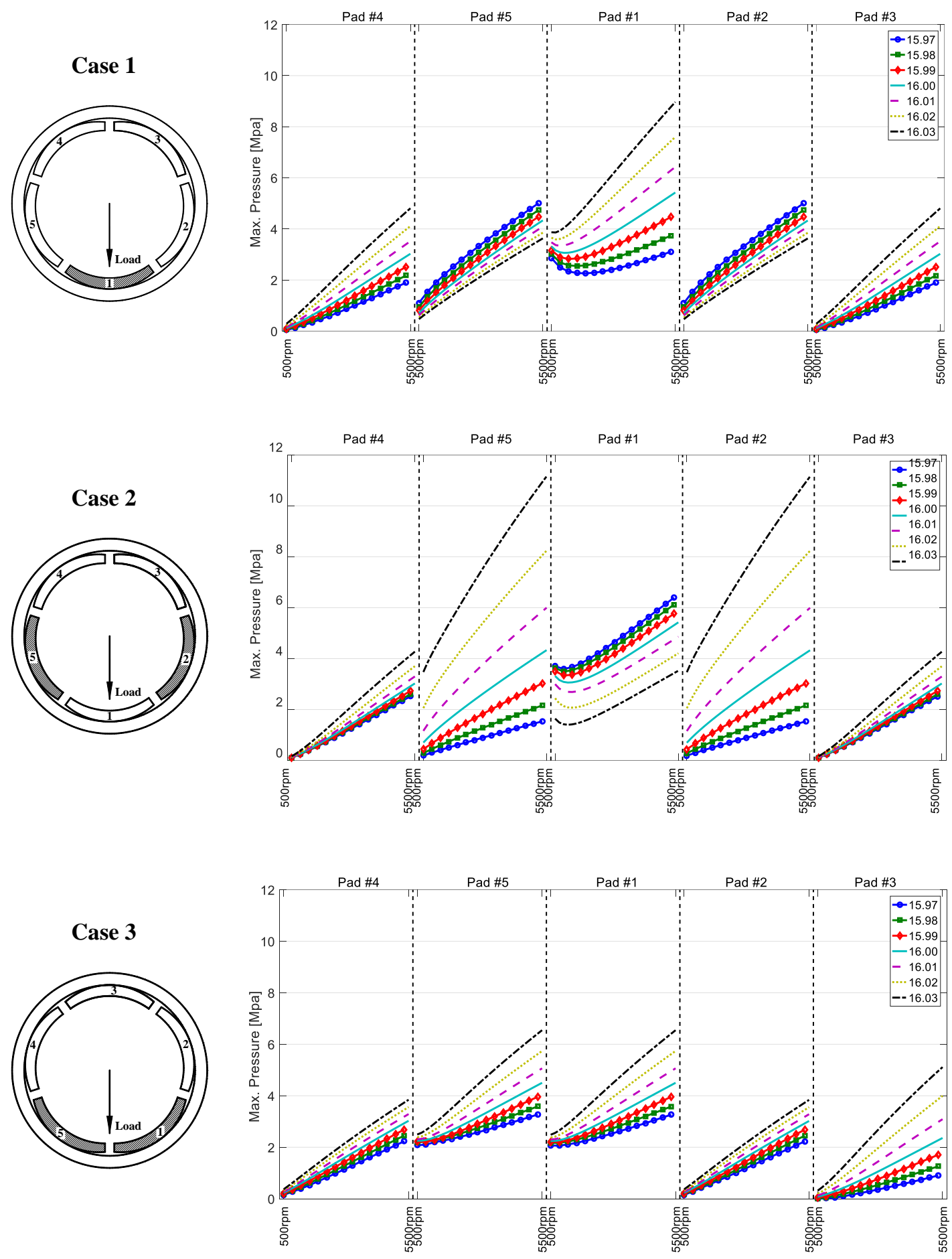

Fig. 11. Maximum pressure as a function of the rotational speed. 
In general, the maximum pressure increases with the rotational speed except in the first case, where there is an initial decrease. The effect of the pad thickness is clearly noteworthy when the rotational speed is high.

In general, for all three cases, the maximum pressure in the oil film of the bearing increases with the preload of one or two pads.

Moreover, case 2 shows the highest pressure (about $11 \mathrm{MPa}$ at $5500 \mathrm{rpm}$ ) compared to the other two cases (approximately 7-9 MPa) for the 16.03-bearings.

\subsection{Oil temperature in the pads}

The maximum temperature in each pad for several pad thickness values when the rotational speed increases from $500 \mathrm{rpm}$ to $5500 \mathrm{rpm}$ is shown in Fig. 12. In general, the bearing metal temperature strongly depends on the rotational speed [25]. The temperature on the pad increases proportionally to the rotational speed. This is because of the growth in the shear rate which is associated with the increase of velocity gradients across the oil film thickness [26]. Because of the symmetric configuration, there is a similarity in the temperature distribution on pads \#2 and \#5 and on pads \#3 and \#4.

In general, for all three cases, increased pad thickness or pad preload causes an increase in the maximum oil temperature in the pad or pads, where the variation of the preload occurs. An increase in temperature also occurs in the pads in the opposite direction of the pad with the preload variation. For example, for the LOP configuration of case 1, a variation of the preload on pad \#1 produces an increase in the oil temperature in pads \#1, \#3 and \#4 and a decrease in lateral pads \#2 and \#5.

It is interesting to note that, in the case 2 when the static load is applied in the middle of pad \#1, the oil temperature in the unloaded pads (pads \#2 - \#5) increases with the growth of thickness in the two noncontiguous pads in which the oil temperature in pads \#2 and \#5 increases at a rate much greater than that in pad \#3 and \#4, especially at the 16.03-bearing. An opposite trend shows for the oil temperature in pad \#1. The explanation for this behavior relates on the sharing of the applied 
static load on pad \#2 and pad \#5 (as discussed in the previous section). For example, for the 16.03bearing, pad \#2 and pad \#5 support almost the applied static load resulting in the highest temperature among five pads in the same operating condition.

By comparing the cases with the variation of the preloads on two pads (cases 2 and 3), the LBP configuration (case 3) is better than the LOP configuration of case 2 because the temperature increase is more restrained.

Furthermore, in the case of the LBP configuration (case 3), when no high dynamic performance is required, the bearing temperature can be reduced by reducing the preload of the loaded pads.

Industrial bearings are often equipped with only one temperature probe, which is installed in the loaded pad of each bearing. In rotating machinery, the difference of this bearing temperature is used during the alignment procedure of the machine to optimize the load distribution on more bearings. By equipping all pads with temperature probes, possible manufacturing or assembly errors of the bearing can be detected. 

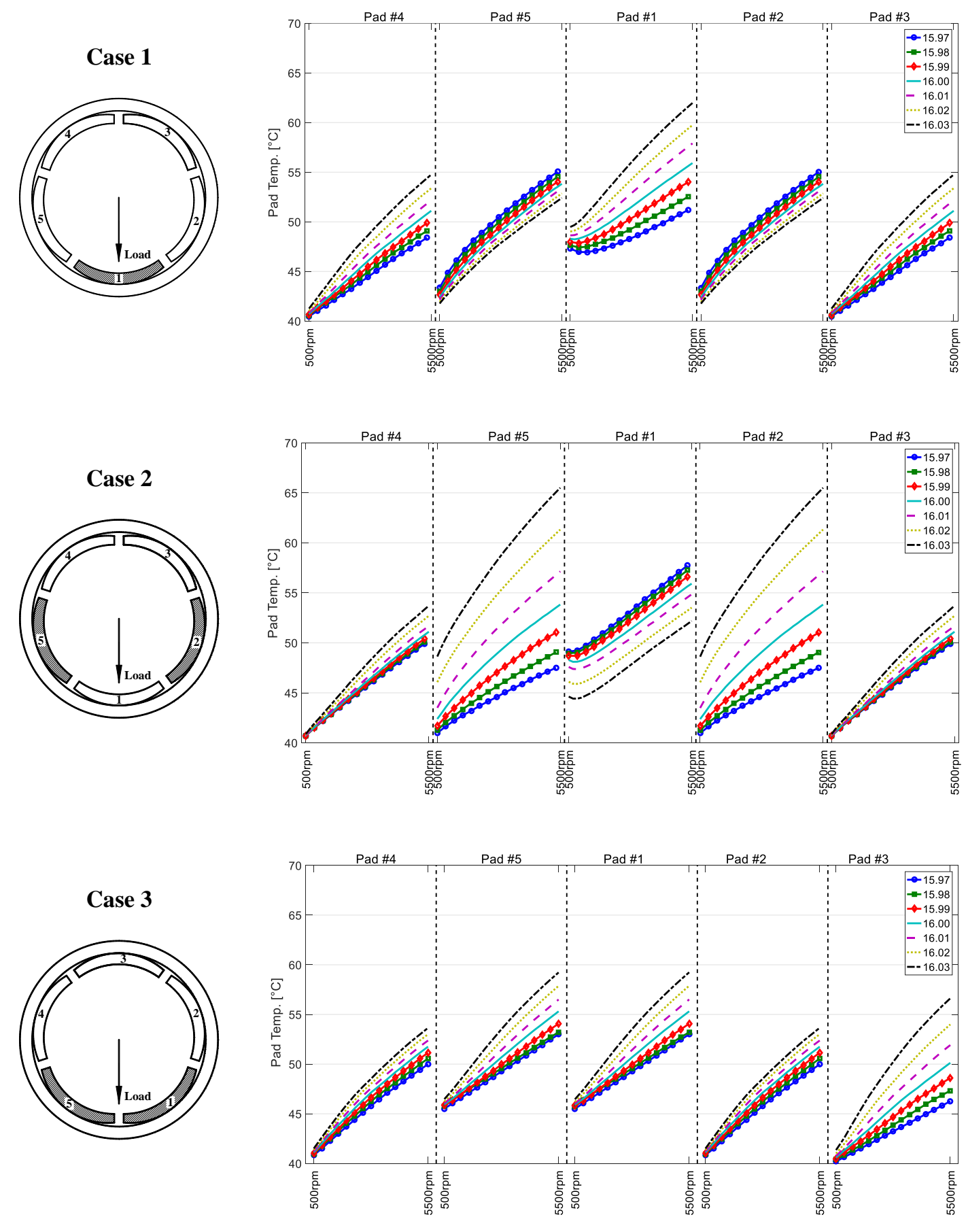

Fig. 12. Maximum oil-temperature on each pad as a function of the rotational speed. 


\subsection{Dynamic coefficients}

The current trend in the industrial field is to increase the dynamic performances of rotating machinery by installing high-preloaded TPJBs to obtain high dynamic coefficients ([20],[21]). Therefore, manufacturing errors in the loaded pads are notably critical to the dynamic behaviour of the machine.

The dynamic stiffness and damping coefficients of all bearings as a function of the rotational speed are shown in Fig. 13 and Fig. 14 for all three cases. For brevity, only the direct terms of the dynamic coefficients are presented here.

Considering the direct stiffness coefficients in Fig. 13, it is possible to observe that a variation of the pad preload can significantly change the direct term in the direction of variation.

In the evaluation of the dynamic coefficients also the pivot stiffness is influenced by the change in the share of load carrying for each pad as a consequence of the pad thickness variation.

The vertical direction (term $k_{y y}$ ) is more sensible to the variation of the pad thickness for case 1, the horizontal direction $\left(k_{x x}\right)$ for case 2 , and both the vertical and horizontal directions for case 3 . In this viewpoint, the LBP configuration appears more suitable for increasing the dynamic of the bearing by intentionally increasing the preload of the loaded pads.

For example, considering case 1 at high speed $(5500 \mathrm{rpm})$, the value of the direct stiffness term $k_{y y}$ of the 16.03-bearing is approximately 2.2 times that of the 15.97-bearing.

An abnormal behaviour occurs for the $k_{y y}$ of the 16.03-bearing in the case 2 . This coefficient first maintains the smallest value at low shaft speed (less than $2500 \mathrm{rpm}$ ) and then reaches the maximum value at high shaft speed (more than $5000 \mathrm{rpm}$ ).

Similar effects for a variation of the pad thickness are observed in the damping coefficients in Fig. 14, where the coefficients increase in the same direction as the variation of the pad thickness. In this case, the increase of the corresponding damping direct term is not significant for the stiffness 
term. For example, considering case 1 at high speed $(5500 \mathrm{rpm})$, the direct damping term $c_{y y}$ of the 16.03-bearing is approximately 1.5 times that of the 15.97 -bearing.
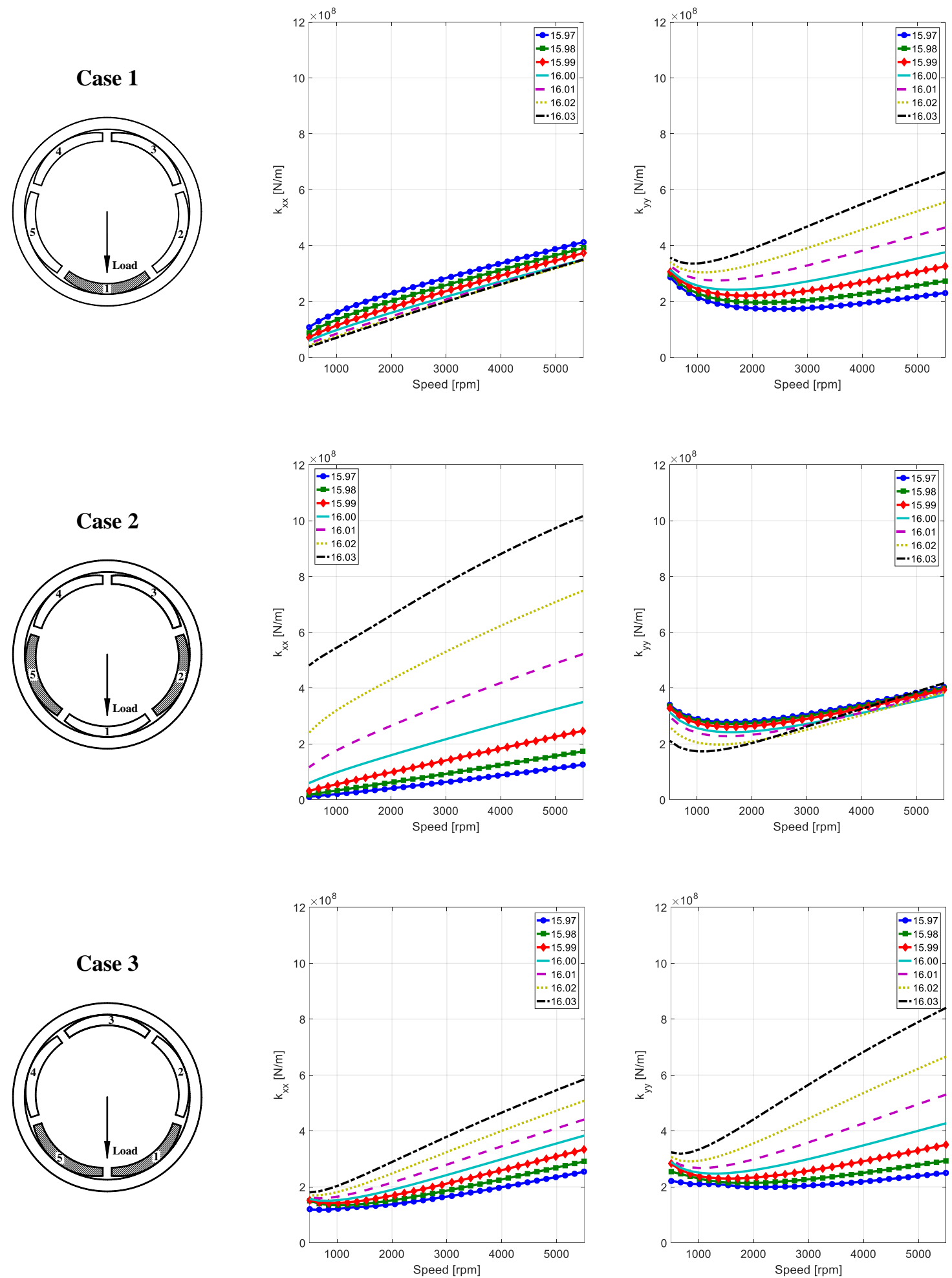

Fig. 13. Stiffness coefficients vs. rotational speed. 

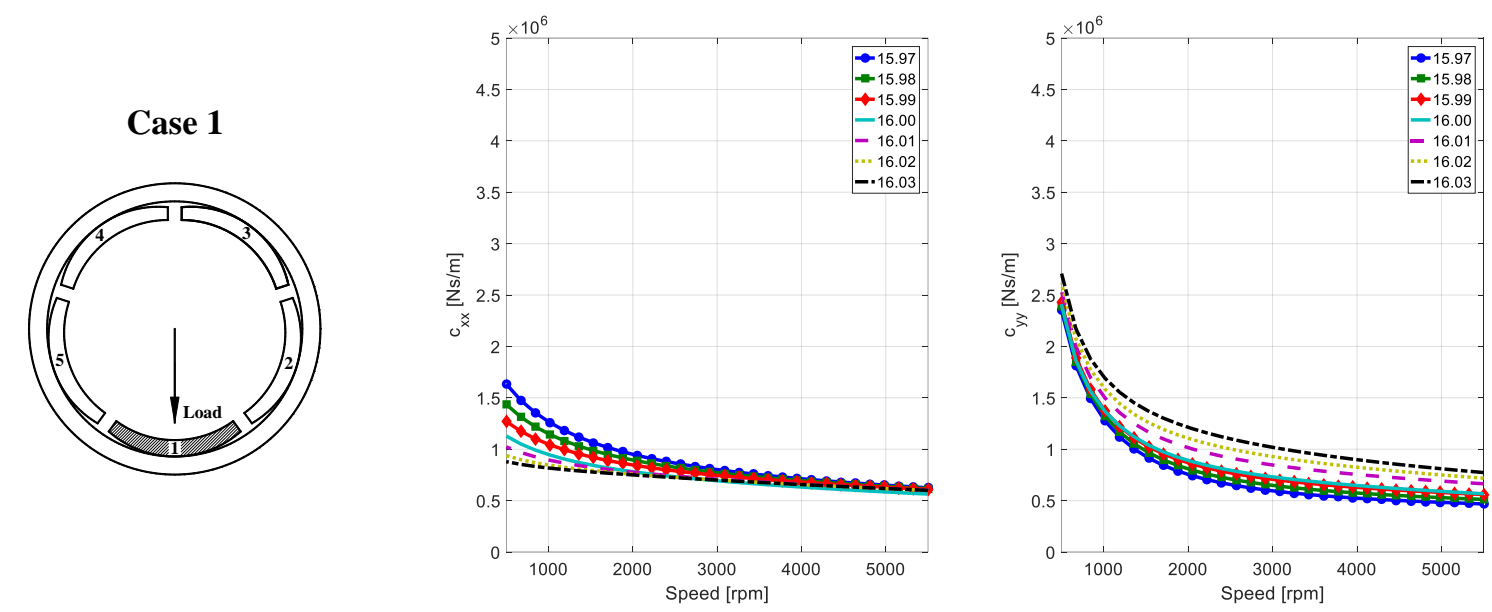

Case 2
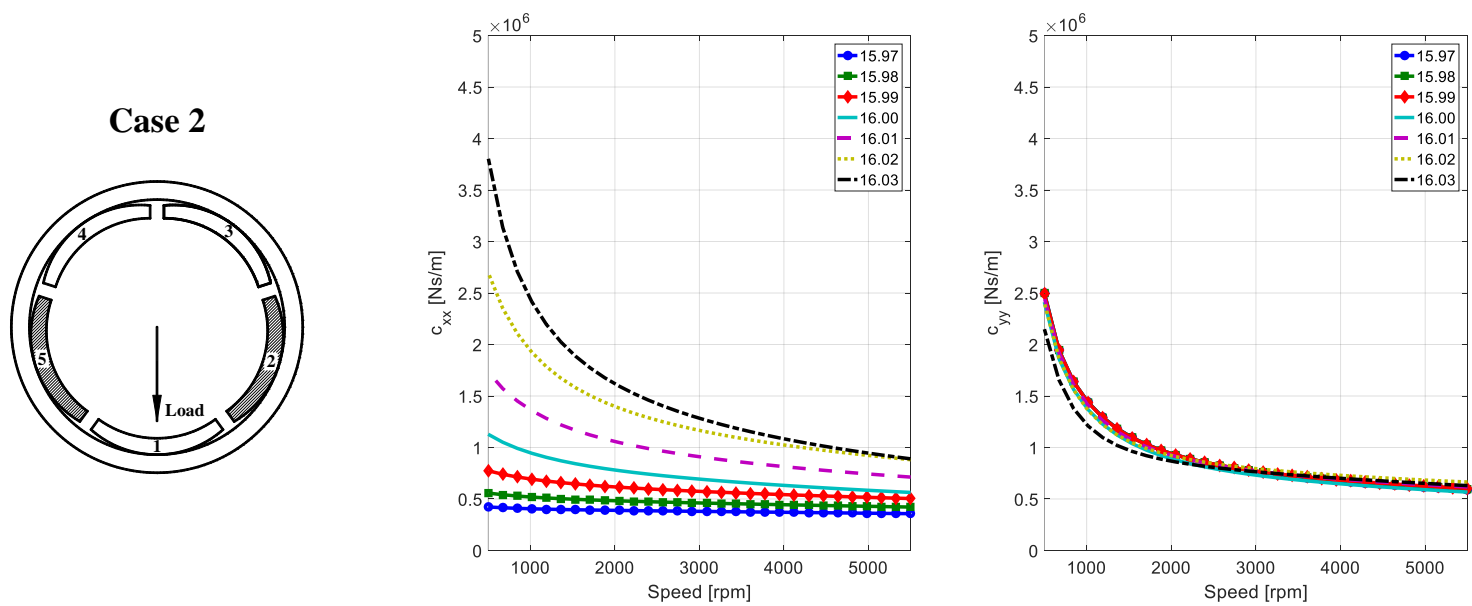

Case 3
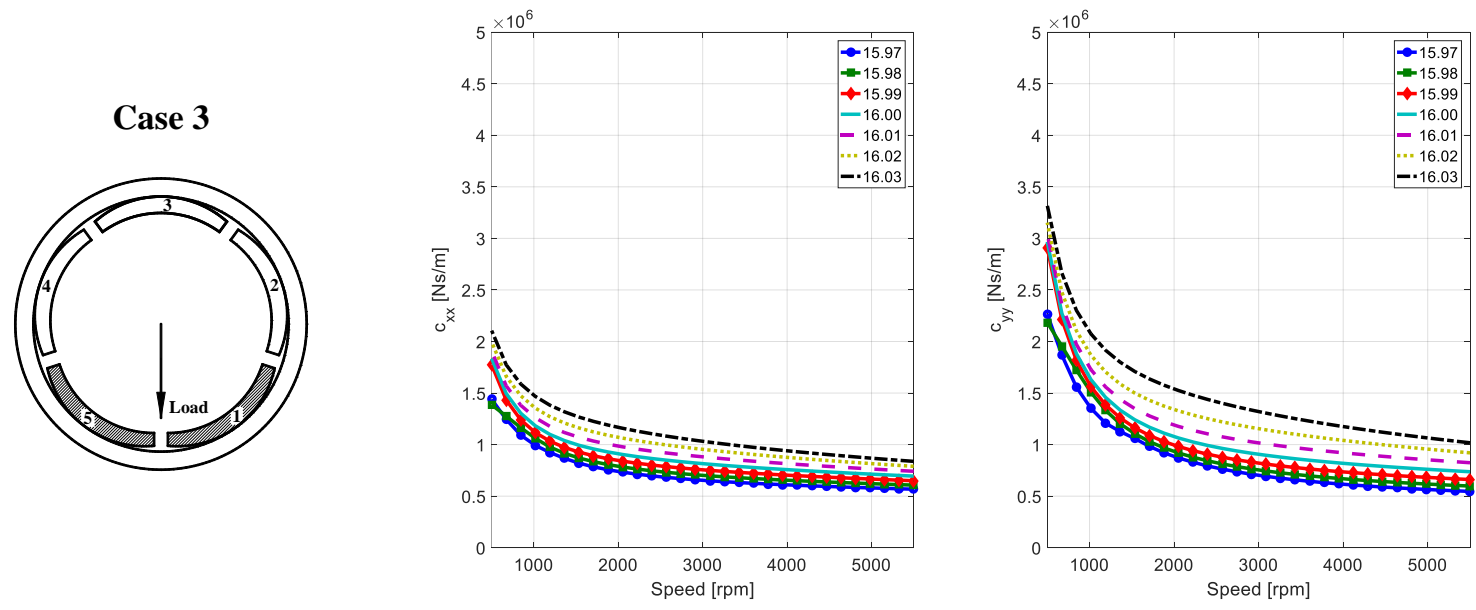

Fig. 14. Damping coefficients vs. rotational speed. 


\subsection{Effect of the angular position of the bearing}

In this section, the effect of the angular position of the bearing (see Fig. 7) is investigated.

In general, if the presence of possible manufacturing or assembly errors cannot be excluded a priori, the angular position, that is, the pad in which this error occurs, is unknown. This analysis aims to investigate the effect of the thickness errors when these errors occur not necessarily in the loaded pad(s). In addition, the actual direction of the load in some application is not exactly known.

The analysis was performed by fixing the static load in the downward direction, rotating and changing the thickness of pad \#1. This condition also corresponds to a fixed bearing for which the load changes direction and is obtained by simply changing the reference system.

\subsubsection{Shaft locus}

The effect of the pad thickness on the shaft locus is shown in Fig. 15 using the rotating reference system of the bearing for several angular positions of the bearing. For the nominal bearing, the shaft locus has a "smooth" pentagon shape as plotted in Fig. 15(a) (which appears as a circular shape with a radius of approximately $26 \mu \mathrm{m})$. This shape occurs because the clearance profile creates a polygon for a TPJB, in which the number of sides corresponds to the number of pads in the bearing [11]-[13],[16]-[17]. Abnormal shapes are presented for the shaft locus of other bearings. In particular, the shaft locus shape deforms according to the variation of the pad thickness. 


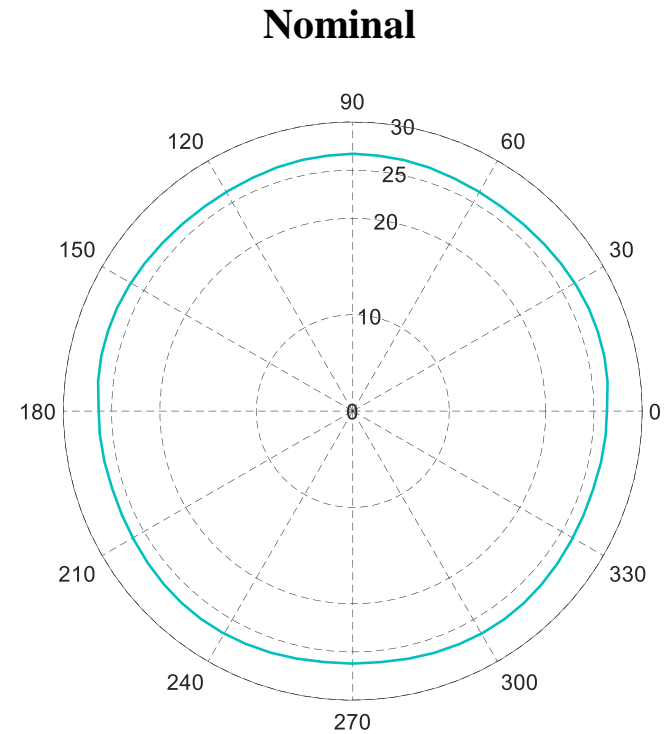

(a)
Case 1

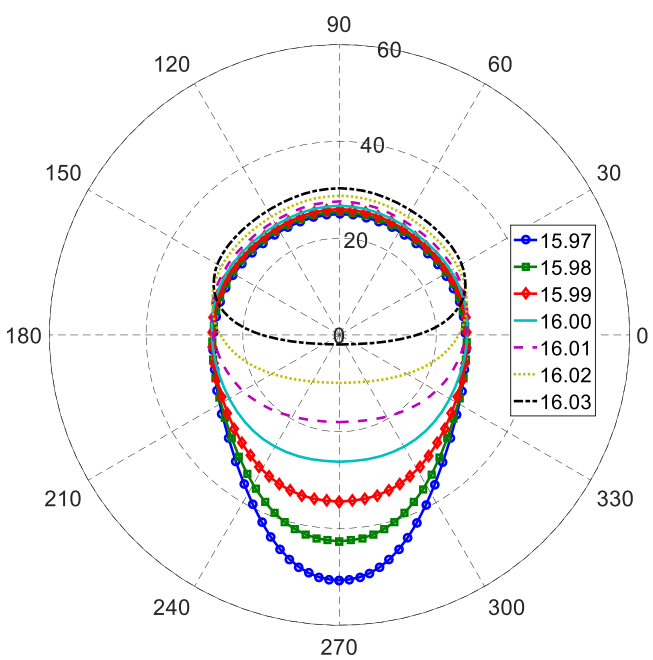

(b)

Fig. 15 Shaft locus of the nominal bearing in the bearing reference system vs. the bearing angular position (a); shaft locus of all bearings vs. the bearing angular position (b).

\subsubsection{Minimum oil film thickness and maximum pressure}

The minimum oil film thickness of the nominal bearing (16.00-bearing) periodically changes with the angular position of the bearing as plotted in Fig. 16, reaching its highest value for LBP configurations (from $-90^{\circ}$ to $270^{\circ}$ with a step of $72^{\circ}$ ) and lowest value for LOP configurations (from $-54^{\circ}$ to $234^{\circ}$ with a step of $72^{\circ}$ ). This result is less evident for other non-nominal bearings because of the asymmetric clearance distribution.

Moreover, the peak-to-peak oil film thickness of these non-nominal bearings increases compared with the nominal one. Interestingly, when the static load is applied to the LOP for pad \#1, there is an evident difference in the minimum film thickness among all bearings in comparison with other positions of the static load.

Compared to the minimum film thickness, a similar trend is obtained for the maximum pressure as a function of the angular position of the bearing (Fig. 17). The maximum pressure of the nominal 
bearing periodically changes with small fluctuations, and the LBP configurations have the smallest maximum pressure.

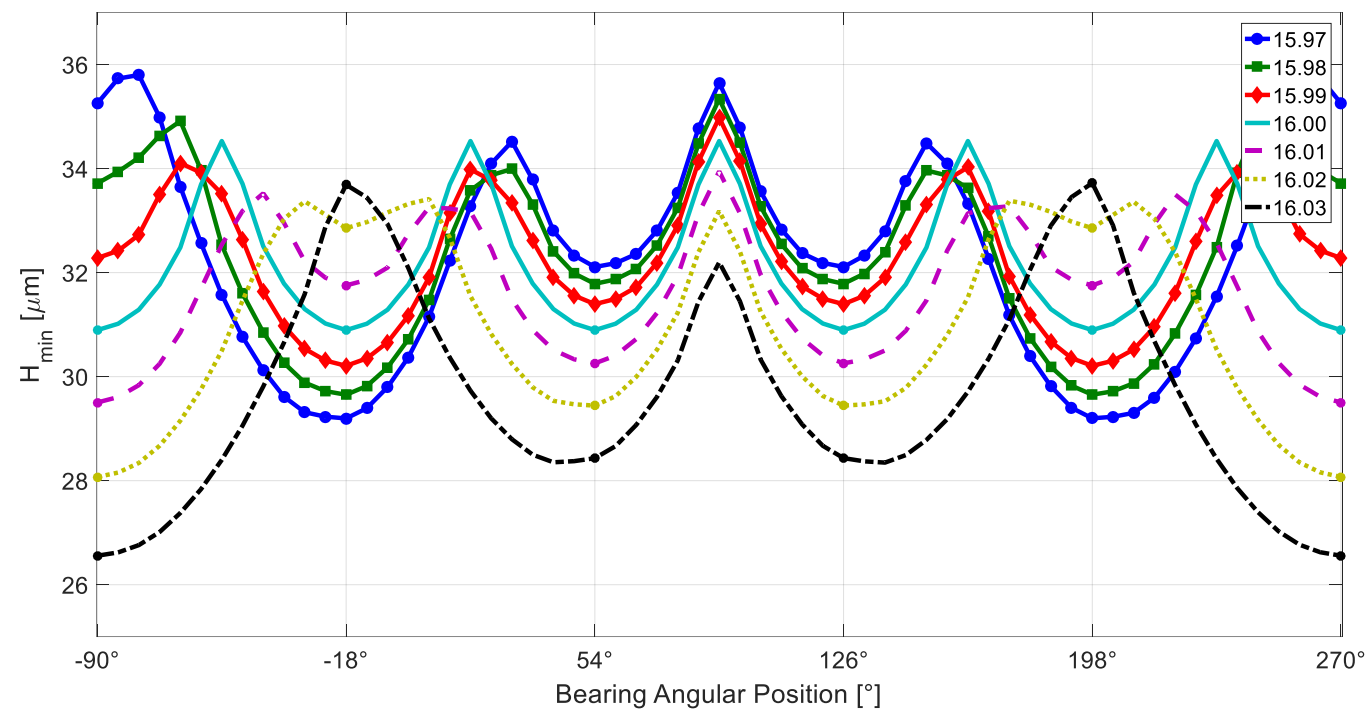

Fig. 16. Minimum oil film thickness as a function of the bearing angular position.

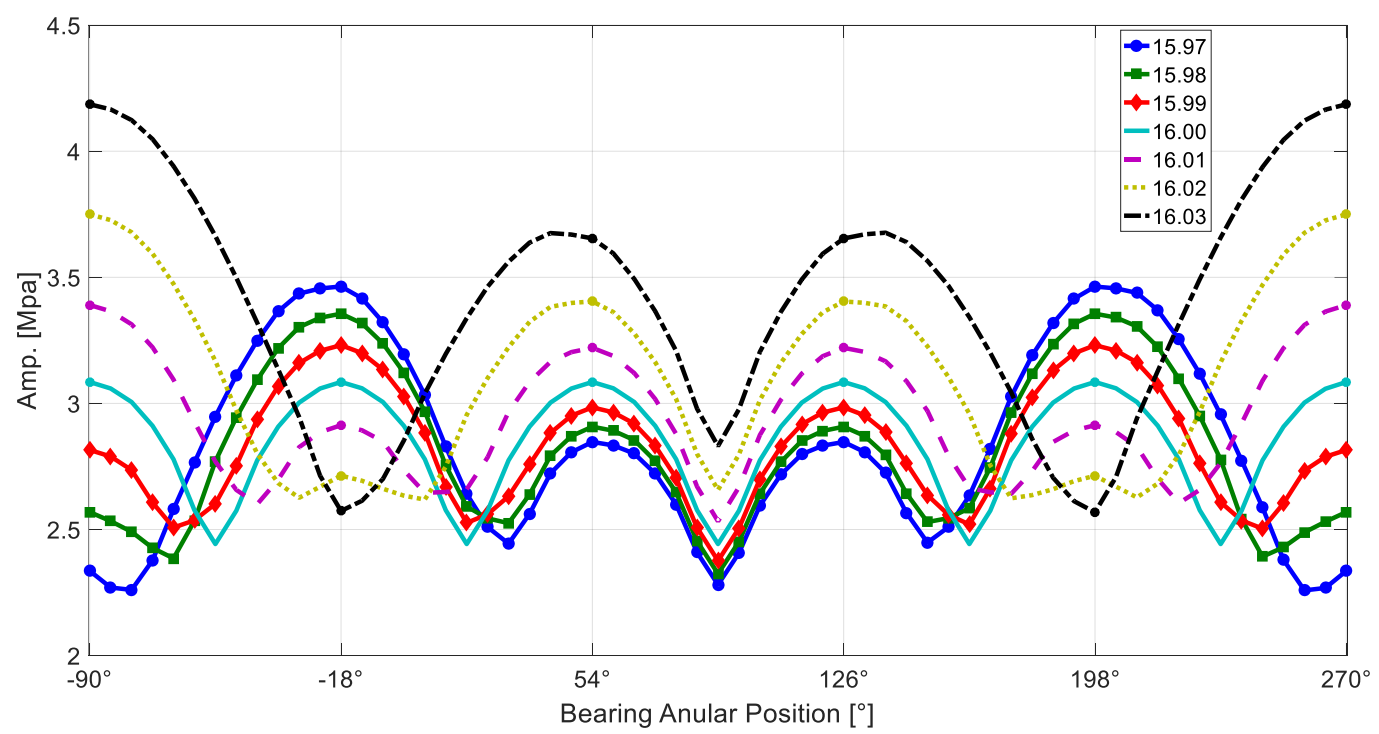

Fig. 17. Maximum pressure as a function of the bearing angular position 


\subsubsection{Oil temperature in the pads}

The maximum temperature of the oil in the pads is shown in Fig. 18. Because the thickness variation only occurs on pad \#1, its effect on the temperature distribution of pad \#1 is more evident when pad \#1 is loaded. However, for low static load and low rotational speed, the pad thickness hardly affects the temperature. At $-90^{\circ}$ or $270^{\circ}$ (LOP for pad \#1), the difference in temperature on pad \#1 for the 15.97-bearing and 16.03-bearing is nearly $4{ }^{\circ} \mathrm{C}$ (approximately $10 \%$ ).

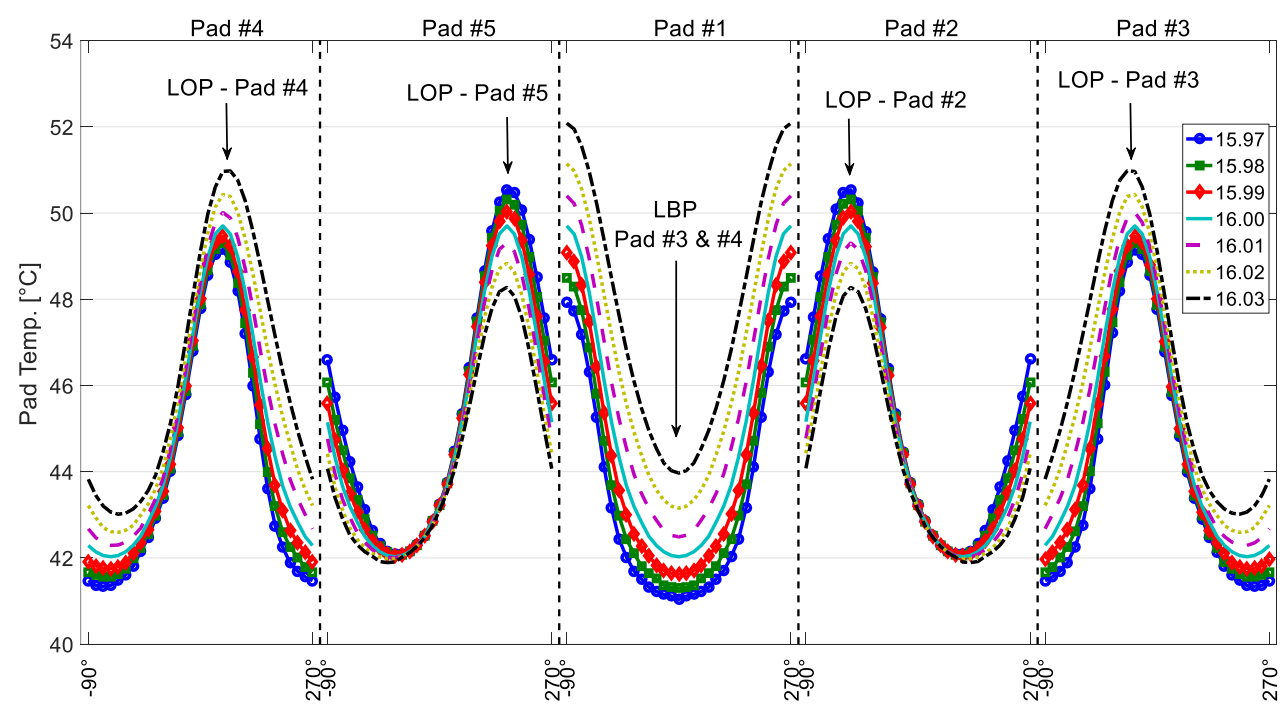

Fig. 18. Temperature distribution on each pad as a function of the bearing angular position.

\subsubsection{Dynamic coefficients}

The effect of the angular position of the bearing on the direct terms of the dynamic stiffness and damping coefficients for the bearings is shown in Fig. 19. As stated, the static load is fixed in the downward direction; i.e., the absolute reference system is assumed in the diagrams. The dynamic coefficients for the nominal bearing (16.00-bearing) periodically change as a function of the angular rotation of the bearing, oscillating from the LOP configuration to LBP configuration. This periodicity does not occur for the non-nominal bearings because of the asymmetric geometry.

The stiffness $\left(k_{x x}\right)$ and damping coefficients $\left(c_{x x}\right)$ in the unloaded direction at $-18^{\circ}$ and $198^{\circ}$ (corresponding to LOP for pads \#2 and \#5, respectively) increase with an increase in pad thickness. 
On the contrary, these dynamic coefficients show an opposite trend at $-90^{\circ}$ (LOP for pad \#1). In addition, there are no significant variations for $k_{x x}$ and $c_{x x}$ when the static load is applied on pads \#3 (LOP at $54^{\circ}$ ) and \#4 (LOP at $\left.126^{\circ}\right)$.

However, the dynamic coefficients in the vertical direction $\left(k_{y y}\right.$ and $c_{y y}$ ) show an opposite behaviour in comparison with $k_{x x}$ and $c_{x x}$. They considerably increase at $-90^{\circ}$ and decrease at $-18^{\circ}$ and $198^{\circ}$ with the increase in pad thickness.

A fixed bearing can be considered with the variation of the pad thickness for pad \#1 in the fixed direction, and the effect of the load direction can be analyzed. This case is the case of an unknown load direction. Therefore, the same dynamic coefficients can be plotted by considering a rotating load in the reference system of the bearing, as shown in Fig. 20.

In any case, an increase in thickness (or preload) for pad \#1 generally increases the stiffness and damping coefficients in the vertical direction and decreases them in the horizontal direction. This effect is more significant if the load is in the same direction as pad \#1. 

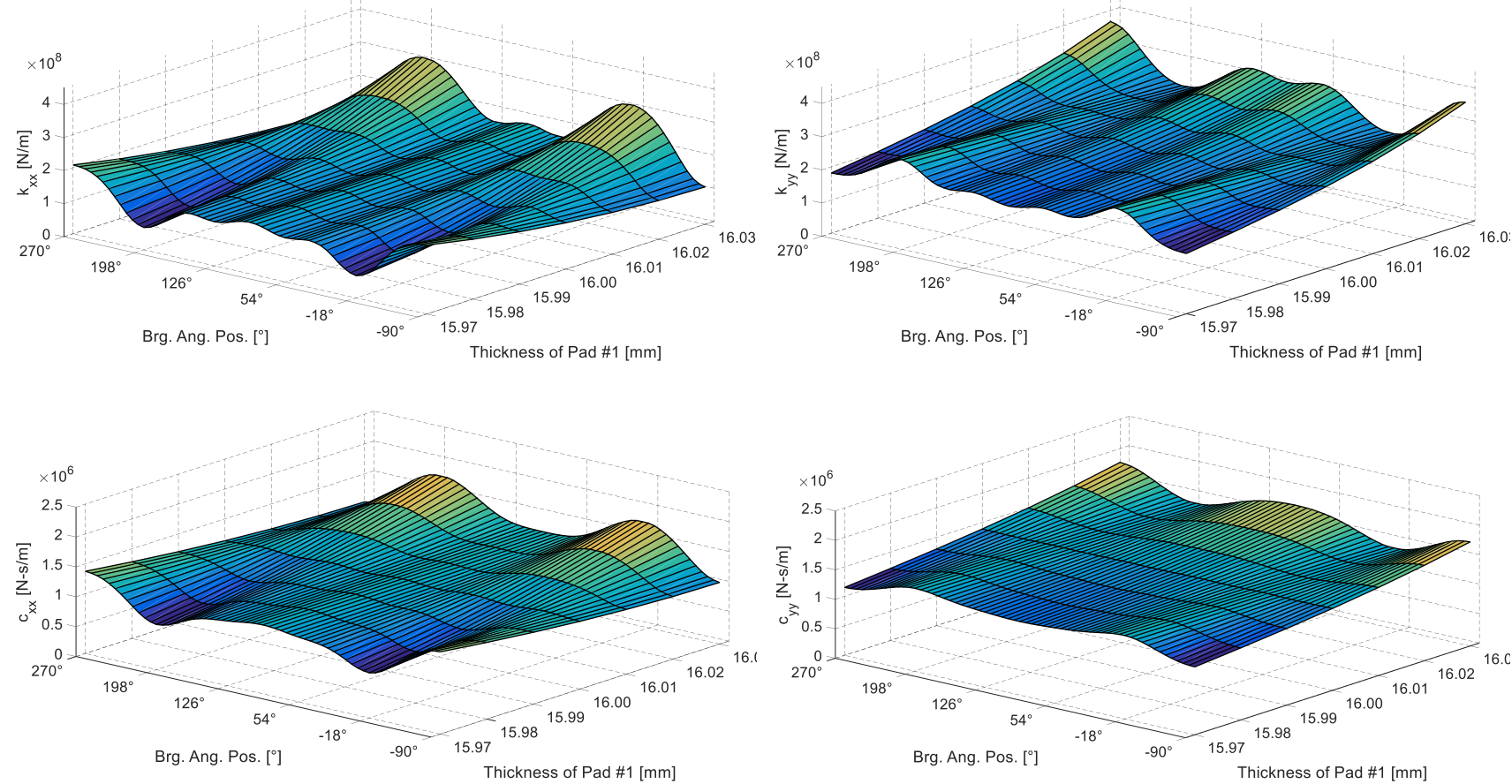

Fig. 19. Dynamic coefficients vs. the bearing angular position in the load reference system.
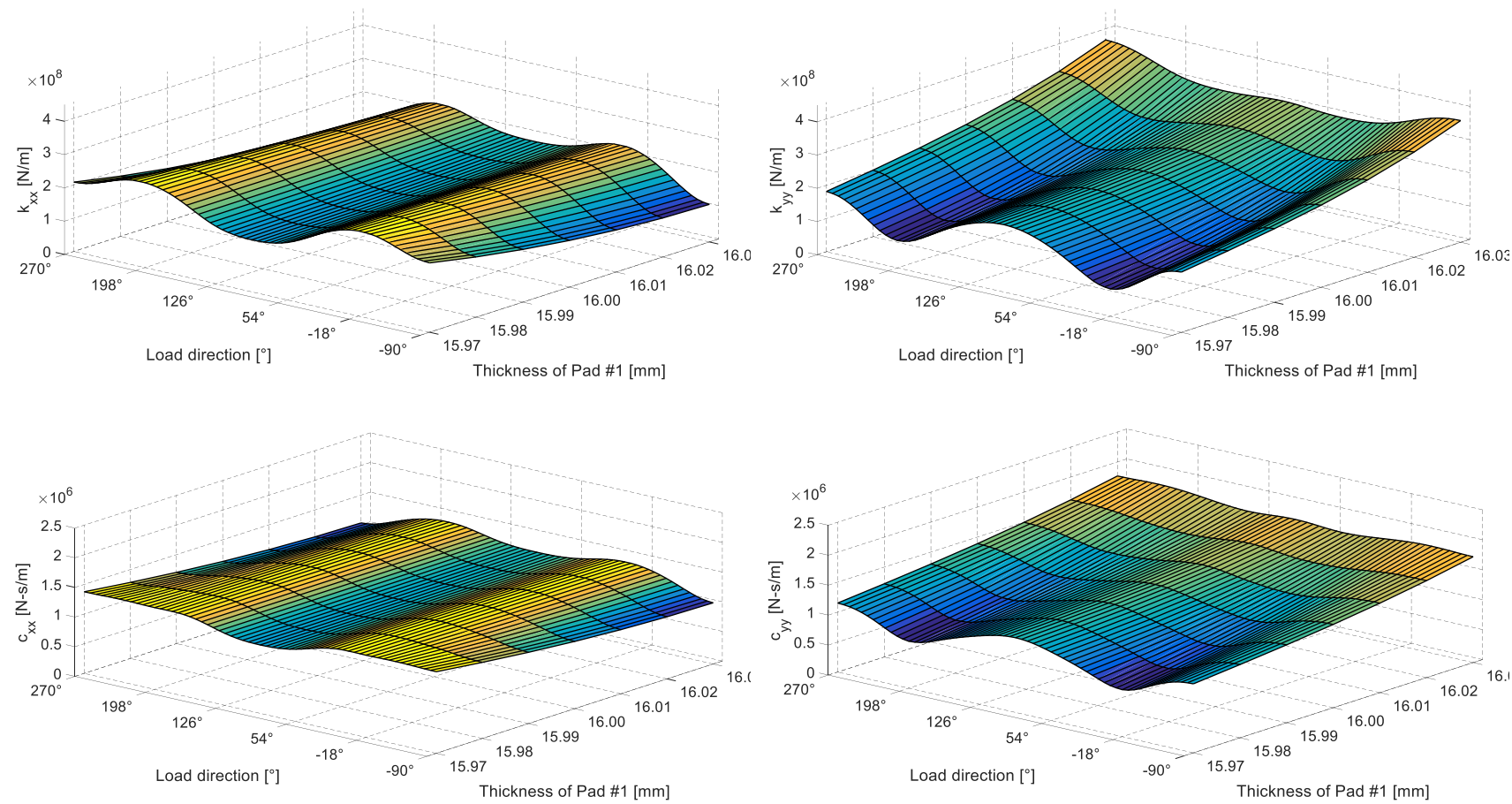

Fig. 20. Dynamic coefficients vs. load direction in the bearing reference system. 


\section{CONCLUSIONS}

In the paper, the effects of a large manufacturing error in the pads of five-pad TPJBs on the static and dynamic behaviours of the bearing were thoroughly investigated using numerical simulations based on a TEHD model. Manufacturing errors can make the actual bearing geometry and dimensions different from the nominal ones. In particular, for TPJBs, the asymmetry of the bearing geometry causes unexpected behaviours of the bearing. The case of manufacturing errors in the pad thickness, which correspond to different pad preloads, was considered.

Three cases of thickness variation were considered for the parametric analysis, which affected one or two pads simultaneously. Results concerning the static position of the shaft centre, minimum film thickness, maximum pressure, maximum temperature of the oil in the pads, and dynamic coefficients as a function of the rotational speed are presented and discussed. For the first case, the angular position of the bearing or the load direction is also analyzed. The following conclusions are drawn from the numerical results:

1. Manufacturing errors in the pad thickness remarkably affect the shaft locus, minimum oil film thickness and maximum pressure on the pads, particularly at high rotational speed.

2. Manufacturing errors weakly affect the flow rate and power loss of the bearing. These two quantities have not been reported in the paper for the sake of brevity. A slight increase in power loss is observed for an increase in preload (pad thickness). The increase in the power loss is due to the increase of the shear stresses in the oil. These are due to the increase in the gradient of the pressure along the tangential direction and to the reduction of the oil-film thickness.

3. The main effect of a change in pad thickness is a different share of load carrying for each pads. In general, the increase in the pad thickness corresponds to the increase in the pressure for the $\operatorname{pad}(s)$ in which the pad thickness variation occurs and for the pad(s) placed in the opposite direction. Furthermore, for case 2, the pressure has the largest increase with the increase in pad preload, among the three cases. 
4. In general, the consequence of a pressure increase when the pad thickness increases in the loaded pad(s) (LOP or LBP) (cases 1 and 3), is a reduction of the minimum oil film thickness.

5. The variation of thickness in noncontiguous pads (case 2) is peculiar: a positive or a negative variation of the pad thickness with respect to the nominal value causes a decrease in the minimum oil film thickness at the highest shaft speed. In the case of an increase in pad thickness, the applied static load is shared on the two noncontiguous pads even if the load is applied in the middle of pad \#1 (in the vertical direction). To avoid an unsafe reduction of the minimum oil film thickness, the LBP configuration is more robust against problems that arise from the manufacturing errors of the pad. The worst condition for the minimum oil film thickness is given by the LOP configuration (case 2) with the pad thickness of $16.03 \mathrm{~mm}$, in which a reduction of $50 \%$ has been highlighted in comparison with the nominal condition. Consequently, the maximum pressure of the 16.03-bearing is $300 \%$ higher than that of the nominal one.

6. The temperature of the oil increases in pads in which the pressure increases and the oil film thickness decreases.

7. Manufacturing errors considerably affect the dynamic behaviour of the bearing, particularly for small bearings with high preloads. In general, an increase in pad thickness causes an increase in dynamic coefficients (stiffness and damping) mainly in the direction of the variation. For example, considering case 1 at high speed $(5500 \mathrm{rpm})$, the value of the direct stiffness and damping term $k_{y y}, c_{y y}$ of the 16.03 -bearing is approximately 2.2 times and 1.5 times those of the 15.97-bearing. If the objective is the increase in dynamic performances of the machine by an increase in preload, this condition can be achieved simply by increasing the thickness of the loaded pad(s). From this viewpoint, the LBP configuration is preferable, as the dynamic coefficients increase in both the vertical and horizontal directions for a positive change in thickness of the loaded pads. 
8. The minimum oil film thickness, maximum pressure, dynamic coefficients of the nominal bearing periodically changes with the angular position of the bearing. The fluctuation of dynamic coefficients in a full revolution of the angular position of the bearing is minimum for the nominal bearing and is maximum in the worst case of variation of pad thickness. In particular, the asymmetry of the clearance distribution increases the anisotropy of bearing dynamic behaviour that is the dynamic coefficients in the vertical and horizontal directions are more different.

\section{Declaration of Conflicting Interests}

The author(s) declared no potential conflicts of interest with respect to the research, authorship, and/or publication of this article. 


\section{References}

[1] Lund JW. Spring and damping coefficients for tilting pad journal bearing. Trans ASLE 1967; 7: $342-352$.

[2] Jones GJ, Martin FA. Geometry Effects in Tilting-Pad Journal Bearings. The 33rd Annual Meeting in Dearborn, Michigan 1978.

[3] Wilkes JC, Childs DW. Improving tilting pad journal bearing predictions-part I: model development and impact of rotor excited versus bearing excited impedance coefficients. $J$ Eng Gas Turbines Power 2013; 135(1): 012502.

[4] Simmons F, Varela AC, Santos IF, Glavatskih S. Dynamic characteristics of polymer faced tilting pad journal bearings. Tribol Int 2014; 74: 20-27.

[5] Hou Y, Lai T, Chen S, Ma B, Liu J. Numerical analysis on the static performance of tilting pad-journal gas bearing in subsystems. Tribol Int 2013; 61: 70-79.

[6] Wygant K, Flack R, Barrett L. Measured performance of tilting-pad journal bearings over a range of preloads - part I: static operating conditions. Tribology Transactions 2004; 47(4): $576-584$.

[7] Wygant K, Flack R, Barrett L. Measured performance of tilting-pad journal bearings over a range of preloads - part II: dynamic operating conditions. Tribology Transactions 2004; 47(4): 585-593.

[8] Wang W, Li Q, Gao J, He F, Diamond T, Allaire P. Rotordynamic evaluation of full scale rotor on tilting pad bearings with 0.1 and 0.3 preload. Shock and Vibration 2014. Article ID 314892. 
[9] Strzelecki S. Dynamic characteristics of tilting 5-pads journal bearing with asymmetric support of pads. Sixth International Conference on Rotor Dynamics (IFToMM), University of New South Wales, Sydney, Australia 2002; 807-814.

[10] Wilkes JC, Childs DW. Tilting pad journal bearing - a discussion on stability calculation, frequency dependence, and pad and pivot. J Eng Gas Turbines Power 2012; 134(12): 122508.

[11] Dang PV, Chatterton S, Pennacchi P, Vania A, Cangioli F. Behavior of a tilting-pad journal bearing with different load directions. ASME Paper No. DETC2015-46598; 2015. DOI: http://dx.doi.org/10.1115/ DETC2015-46598.

[12] Dang PV, Chatterton S, Pennacchi P, Vania A, Cangioli F. Behavior of tilting-pad journal bearings with large machining error on pads. ASME Turbo Expo, Paper No. GT GT201656674. DOI: http://dx.doi.org/10.1115/GT2016-56674.

[13] Chatterton S, Pennacchi P, Dang PV, Vania A. A test rig for evaluating tilting-pad journal bearing characteristics. Proceedings of the 9th IFToMM International Conference on Rotor Dynamics, 2014; 21: 921-930, DOI: http://dx.doi.org/10.1007/978-3-319-06590-8_75.

[14] Dang PV, Chatterton S, Pennacchi P, Vania A, Cangioli F. An experimental study of nonlinear oil-film forces in a tilting-pad journal bearing. ASME Paper No. DETC201546601, 2015. DOI: http://dx.doi.org/10.1115/DETC2015-46601.

[15] Chatterton S, Pennacchi P, Dang PV, Vania A. Identification dynamic force coefficients of a five-pad tilting-pad journal bearing. Proceedings of the 9th IFToMM International Conference on Rotor Dynamics 2014; 21: 931-941. DOI: http://dx.doi.org/10.1007/ 978-3319-06590-8_76. 
[16] Chatterton S, Dang PV, Pennacchi P, Vania A. Behaviour of tilting-pad journal bearings in case of large manufacturing errors. Proceedings of the First International Conference of IFToMM Italy 2016; 47: 221-227. http://dx.doi.org/10.1007/978-3-319-48375-7_24

[17] Dang PV, Chatterton S, Pennacchi P, Vania A. Effect of the load direction on non-nominal five-pad tilting-pad journal bearings. Tribol Int 2016; 98: 197-211. DOI: http://dx.doi.org/10.1016/ j.triboint.2016.02.028.

[18] Fillon M, Dmochowski W, Dadouche A. Numerical study of the sensitivity of tilting pad journal bearing performance characteristics to manufacturing tolerances: steady-state analysis. Tribol Trans 2007; 50: 387-400

[19] Dmochowski W, Dadouche A, Fillon M. Numerical study of the sensitivity of tilting pad journal bearing performance characteristics to manufacturing tolerances: dynamic analysis. Tribol Trans 2008; 51: 573-580

[20] Gómez JL, Pineda S, Díaz SE. On the effect of pad clearance and preload manufacturing tolerances on tilting pad bearings rotordynamic coefficients. ASME Turbo Expo 2013, Paper No. GT 2013-95214.

[21] Quintini JCR, Pineda S, Matute JA, Medina LU, Gómez JL, Díaz SE. Determining the effect of bearing clearance and preload uncertainties on tilting pad bearings rotordynamic coefficients. ASME Turbo Expo 2014, Paper No. GT 2014-26773.

[22] San Andrés L, Tao Y, Li Y. Tilting pad Journal Bearings: On bridging the hot gap between experimental results and model predictions. J Eng Gas Turbines Power 2015; 137: 1-11.

[23] Kirk RG, and Reedy SW. Evaluation of pivot stiffness for typical tilting-pad journal bearing designs. J. Vib., Acoustics, Stress, and Reliability in Design 1988; 110:165-171

[24] Pennacchi P, Vania A, Chatterton S. Nonlinear effects caused by coupling misalignment in rotors equipped with journal bearings. Mech Syst Sig Process 2012; 30: 306-322. 
[25] Chatterton S, Dang PV, Pennacchi P, Luca AD, Flumian F. Experimental evidence of a twoaxial groove hydrodynamic journal bearing under severe operation conditions. Tribol Int 2017;109:416-427. DOI: http://dx.doi.org/10.1016/j.triboint.2017.01.014.

[26] Brito FP, Bouyer J, Fillon M, and Miranda AS. Thermal behavior and performance characteristics of a twin axial groove journal bearing as a function of applied load and rotational speed. $5^{\text {th }}$ International Conference on Mechanics and Materials in Design, 2006.

[27] Chatterton S, Pennacchi P, Vania A. Electrical pitting of tilting-pad thrust bearings: Modelling and experimental evidence. Tribol Int 2016; 103: 475-486. DOI: http://dx.doi.org/10.1016/j.triboint.2016.08.003

[28] Suh J and Palazzolo A. Three-dimensional dynamic model of TEHD tilting-pad journal bearing - Part I: theroretical modeling. Journal of Tribology 2015;137. 


\section{LIST OF FIGURE CAPTIONS}

Fig. 1 Geometry and coordinate for a single pad [17]

Fig. 2 Cross section (middle plane) of the temperature distribution in the nominal TPJB at the static load of $5 \mathrm{kN}$ (in the vertical direction) and the rotational speed of $5500 \mathrm{rpm}$ obtained with a three-dimensional thermal model.

Fig. 3 Boundary conditions (a) and pad mesh (b).

Fig. 4 Cross section (middle plane) of the radial deformation of pads in the nominal TPJB at the static load of $5 \mathrm{kN}$ (in the vertical direction) and the rotational speed of $5500 \mathrm{rpm}$.

Fig. $5 \quad$ Main program flowchart.

Fig. 6 Three cases of thickness variation considered in the parametric study.

Fig. 7 Additional cases, in which the thickness varies for pad \#1 and the angular position of the bearing changes.

Fig. 8 Pressure distribution and share in load of the pads.

Fig. 9 Static position of the shaft centre vs. the rotational speed.

Fig. 10 Minimum oil film thickness as a function of the rotational speed.

Fig. 11 Maximum pressure as a function of the rotational speed.

Fig. 12 Maximum oil-temperature on each pad as a function of the rotational speed.

Fig. 13 Stiffness coefficients vs. rotational speed.

Fig. 14 Damping coefficients vs. rotational speed.

Fig. 15 Shaft locus of the nominal bearing in the bearing reference system vs. the bearing angular position (a); shaft locus of all bearings vs. the bearing angular position (b).

Fig. 16 Minimum oil film thickness as a function of the bearing angular position.

Fig. 17 Maximum pressure as a function of the bearing angular position

Fig. 18 Temperature distribution on each pad as a function of the bearing angular position. 
Fig. 19 Dynamic coefficients vs. the bearing angular position in the load reference system.

Fig. 20 Dynamic coefficients vs. load direction in the bearing reference system. 


\section{LIST OF TABLE CAPTIONS}

Table $1 \quad$ Properties of pad materials

Table $2 \quad$ Bearing geometric characteristics and operating conditions.

Table 3 Assembled clearances and preload factors that correspond to the variations of the pad thickness. 